\title{
Remote Operations and Maintenance Framework for Molten Salt Reactors
}

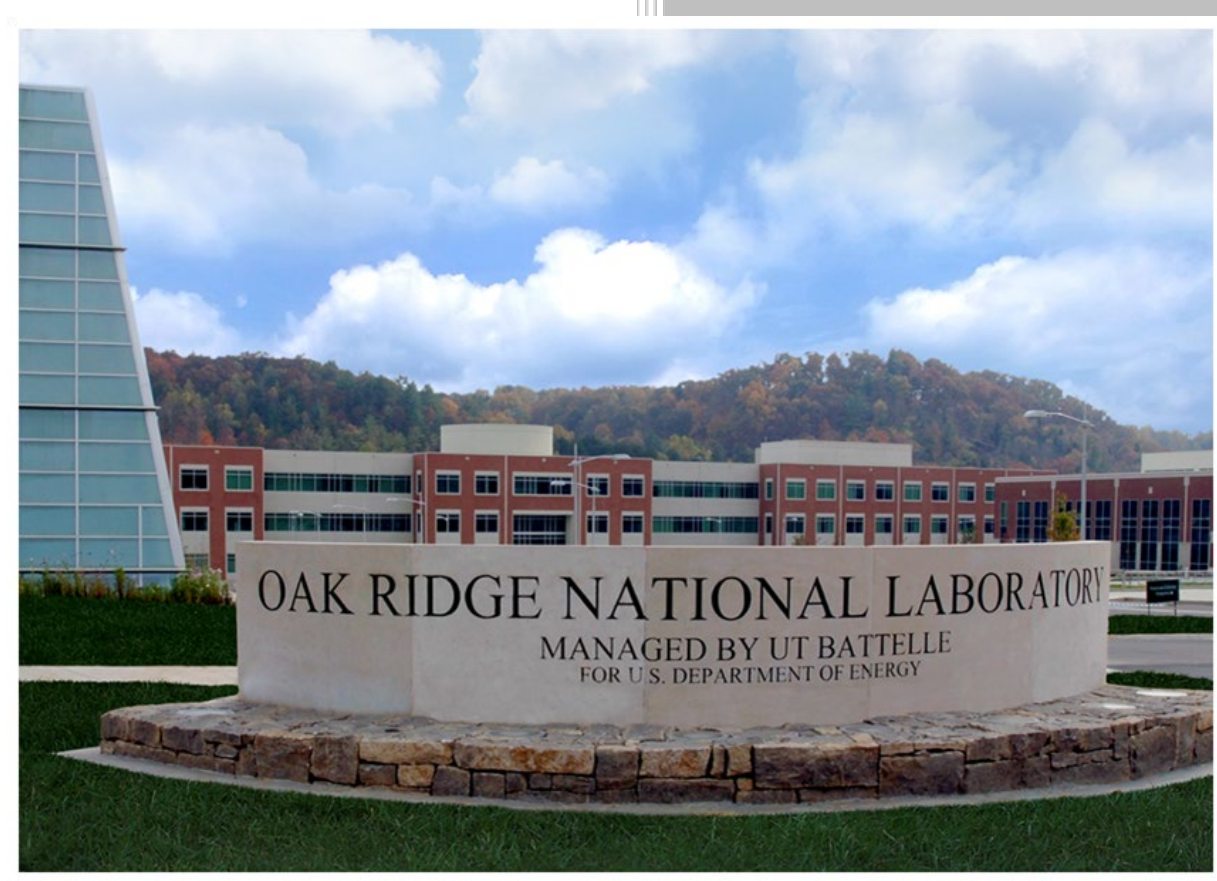

David E. Holcomb Charles L. Britton, Jr. Venugopal K. Varma Louise G. Worrall

December 2018 


\section{DOCUMENT AVAILABILITY}

Reports produced after January 1, 1996, are generally available free via US Department of Energy (DOE) SciTech Connect.

Website www.osti.gov

Reports produced before January 1, 1996, may be purchased by members of the public from the following source:

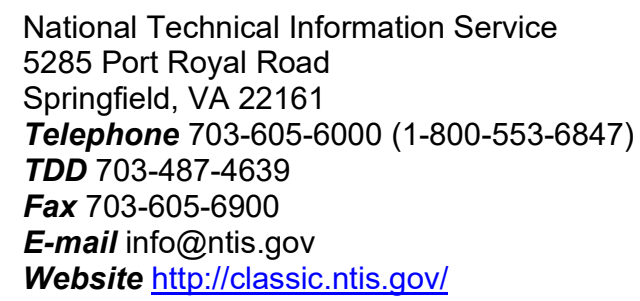

Reports are available to DOE employees, DOE contractors, Energy Technology Data Exchange representatives, and International Nuclear Information System representatives from the following source:

Office of Scientific and Technical Information

PO Box 62

Oak Ridge, TN 37831

Telephone 865-576-8401

Fax 865-576-5728

E-mail reports@osti.gov

Website http://www.osti.gov/contact.html

This report was prepared as an account of work sponsored by an agency of the United States Government. Neither the United States Government nor any agency thereof, nor any of their employees, makes any warranty, express or implied, or assumes any legal liability or responsibility for the accuracy, completeness, or usefulness of any information, apparatus, product, or process disclosed, or represents that its use would not infringe privately owned rights. Reference herein to any specific commercial product, process, or service by trade name, trademark, manufacturer, or otherwise, does not necessarily constitute or imply its endorsement, recommendation, or favoring by the United States Government or any agency thereof. The views and opinions of authors expressed herein do not necessarily state or reflect those of the United States Government or any agency thereof. 
Reactor and Nuclear Systems Division Nuclear Nonproliferation Division

Fusion and Materials for Nuclear Systems Division

\title{
REMOTE OPERATIONS AND MAINTENANCE FRAMEWORK FOR MOLTEN SALT REACTORS
}

\author{
David E. Holcomb \\ Charles L. Britton, Jr. \\ Venugopal K. Varma \\ Louise G. Worrall
}

Date Published: December 2018

Prepared by

OAK RIDGE NATIONAL LABORATORY

Oak Ridge, TN 37831-6283

managed by

UT-BATTELLE, LLC

for the

US DEPARTMENT OF ENERGY

under contract DE-AC05-00OR22725 



\section{CONTENTS}

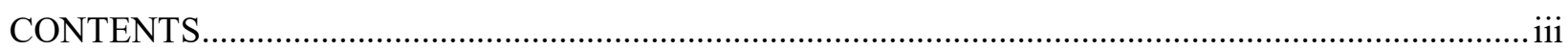

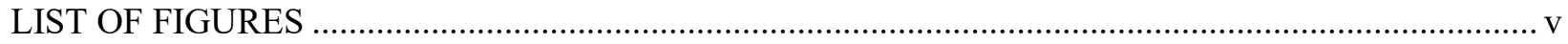

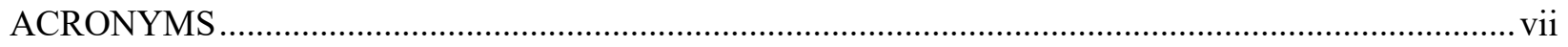

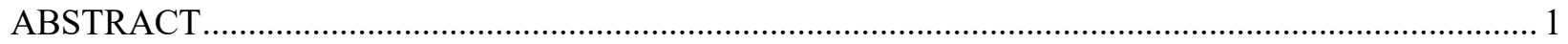

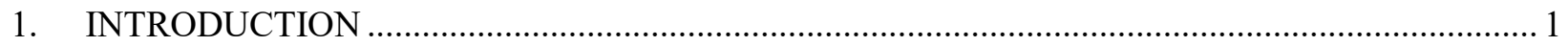

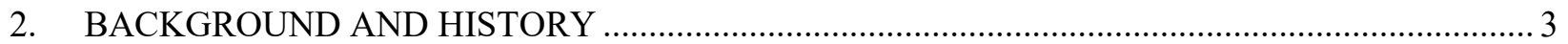

2.1 HISTORIC MOLTEN SALT REACTOR PROGRAM ….................................................. 3

2.2 CONSOLIDATED NUCLEAR FUEL PROCESSING ................................................. 5

2.3 SPALLATION NEUTRON SOURCE …........................................................................ 7

2.4 INTERNATIONAL THERMONUCLEAR EXPERIMENT REACTOR (ITER) .................... 9

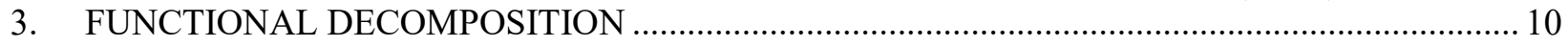

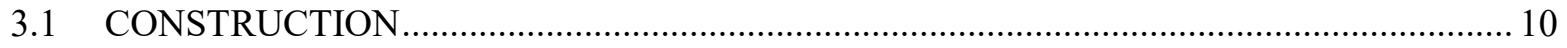

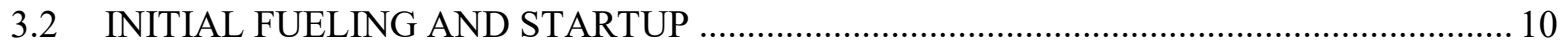

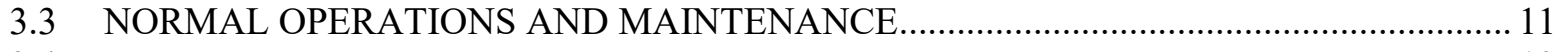

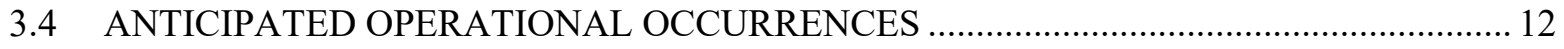

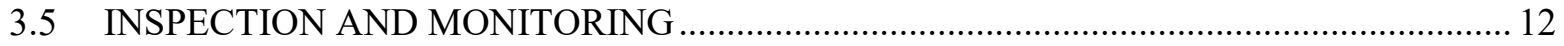

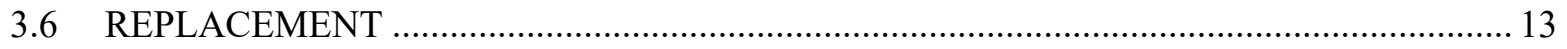

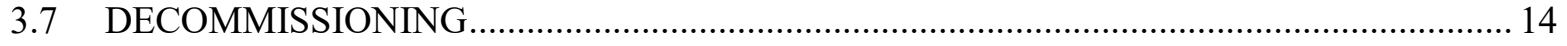

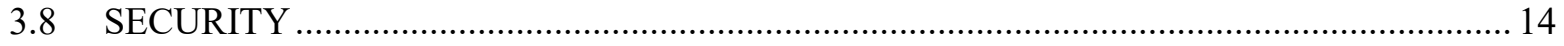

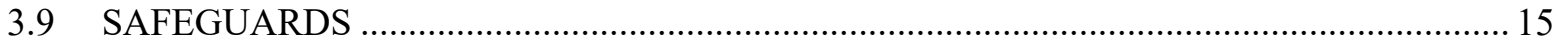

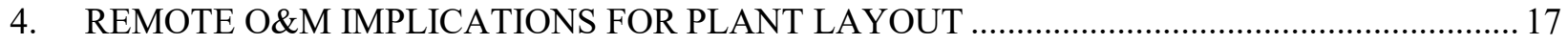

5. REMOTE O\&M TECHNOLOGY OVERVIEW AND MATURITY ASSESSMENT .....................20

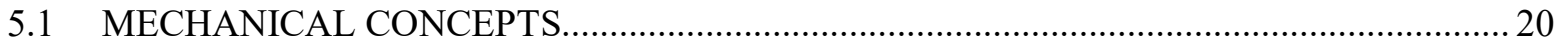

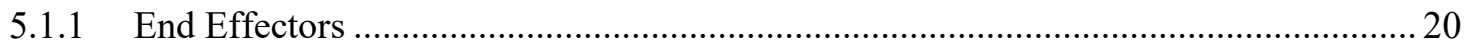

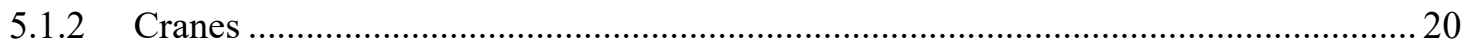

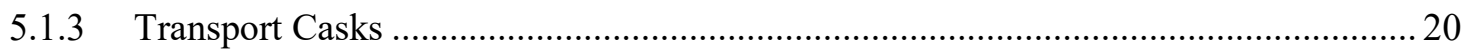

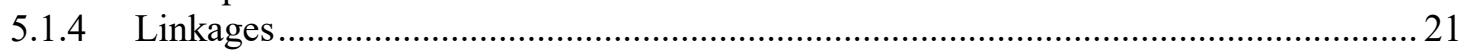

5.1.5 Power Transmission Options (Electrical, Pneumatic, Hydraulic) ............................. 21

5.1.6 Force Feedback via Power Signature ................................................................. 21

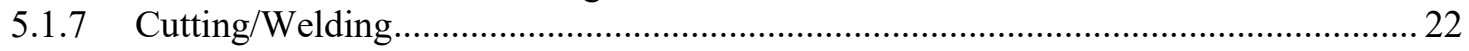

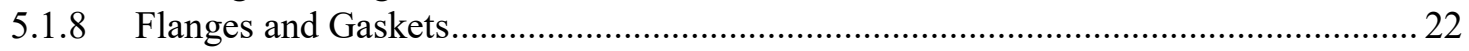

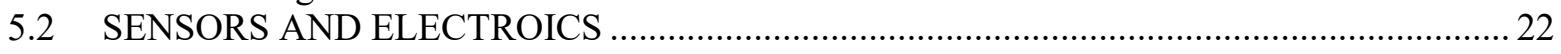

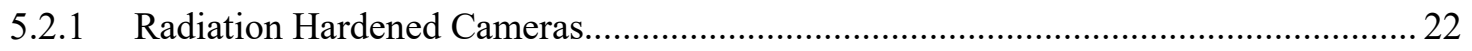

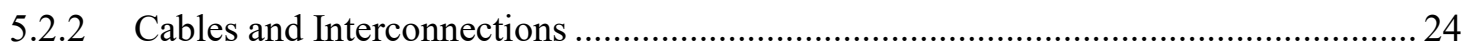

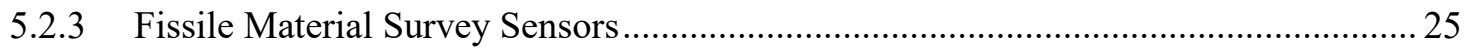

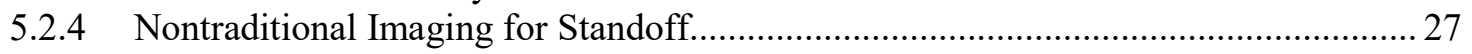

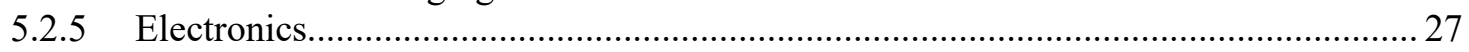

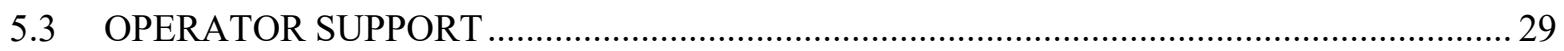

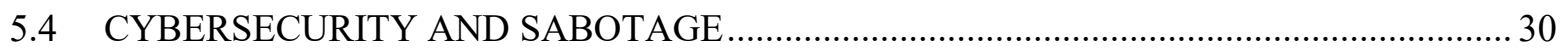

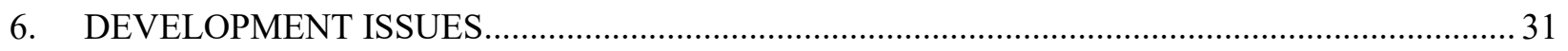

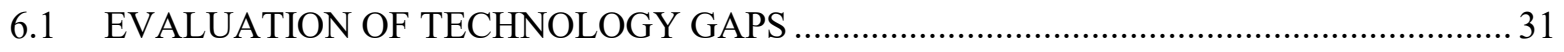

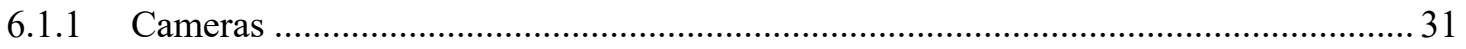

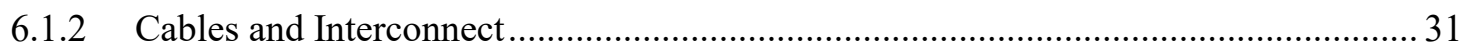

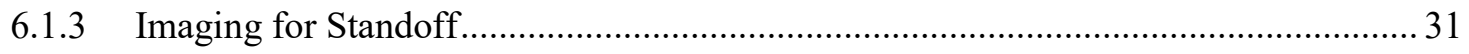

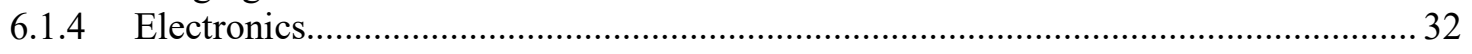

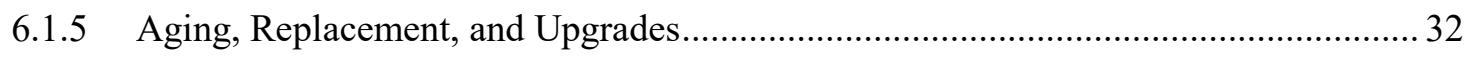

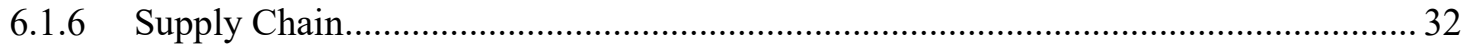

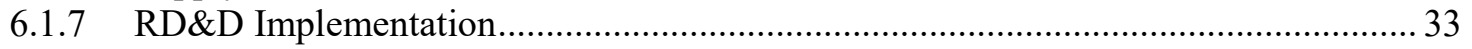




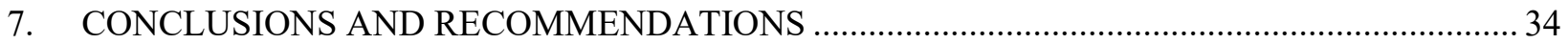

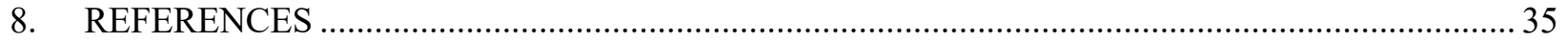




\section{LIST OF FIGURES}

Figure 1. Manipulator arm and pump in hot cell (right) and controlling manipulator via camera and monitor (left) (ORNL photos 42878 and 43068 both from ORNL-CF-58-4-93).

Figure 2. ORNL Remote Maintenance Demonstration Facility. .......................................................... 4

Figure 3. MSRE maintenance planning model (ORNL photo 39417 from ORNL-3419)......................... 5

Figure 4. MSRE maintenance planning model (ORNL photo 39416 from ORNL-3419)......................... 5

Figure 5. M2 servo manipulator in operation (ORNL photo 01677-86) ................................................... 6

Figure 6. Advanced servo manipulator (ORNL Photo 00944-88) …......................................................... 7

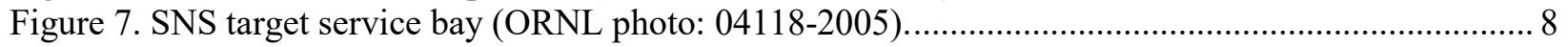

Figure 8. Hot cell bridge crane layout (Drawing No. A-03870929-0) ..................................................... 8

Figure 9. Modified impact wrench (photograph taken by author) ….................................................... 20

Figure 10. Used nuclear fuel cask at ORNL (ORNL photo 2016-P00292).......................................... 21

Figure 11. Graylock flange for remote operation (photograph taken by author).....................................2

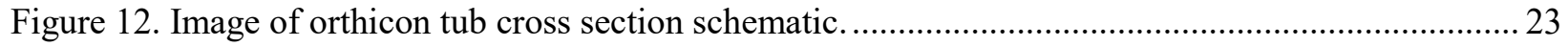

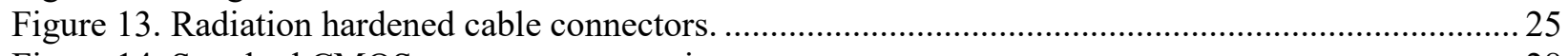

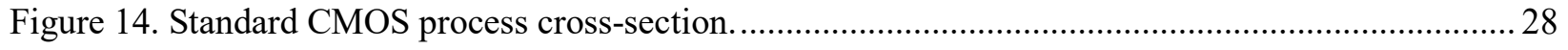





\section{ACRONYMS}

\begin{tabular}{ll} 
AEC & US Atomic Energy Commission \\
ANCC & active neutron coincidence counting \\
APR & active pixel sensor \\
AR & augmented reality \\
ASM & advanced servo manipulator \\
CCD & charge-coupled device \\
CCTV & closed-circuit television \\
CMOS & complementary metal oxide semiconductor \\
CRT & cathode ray tube \\
DDA & differential die-away \\
DDSI & differential die-away self-interrogation \\
DOE & US Department of Energy \\
IAEA & International Atomic Energy Agency \\
ITER & International Thermonuclear Experimental Reactor \\
JFET & junction gate field-effect transistor \\
LiDAR & light detection and ranging \\
LOCA & loss-of-coolant accident \\
LWR & light water reactor \\
M\&S & modeling and simulation \\
MBA & material balance area \\
MI & mineral insulated \\
MSBR & Molten Salt Breeder Reactor \\
MSEC & Molten Salt Engineering Center \\
MSM & master slave manipulator \\
MSR & molten salt reactor \\
MSRE & Molten Salt Reactor Experiment \\
NDA & nondestructive assay \\
NPP & nuclear power plant \\
NRC & US Nuclear Regulatory Commission \\
O\&M & operations and maintenance \\
ORNL & Oak Ridge National Laboratory \\
RD\&D & research, development and demonstration \\
RHBD & rad-hard-by-design \\
RIEMF & radiation-induced electromotive force effect \\
SNS & Spallation Neutron Source \\
SSCs & systems, structures, and components \\
TID & total integrated dose \\
TMR & triple-modular-redundancy \\
TPI & thermoplastic polyimide \\
VR & virtual reality \\
\hline
\end{tabular}





\begin{abstract}
Remote, highly automated operations and maintenance tools (O\&M) are crucial for economically successful deployment of molten salt reactors (MSRs). Liquid-fueled MSRs will have high dose rates within containment following initial start-up due to the proximity of the fuel salt and gaseous fission products. The challenges of performing O\&M in high dose environments have long been recognized, and many of the required technology components have been developed for use in similar high radiation environments.

To be competitive, future MSRs need to have much lower labor costs than existing nuclear power plants. The advance of digital technologies provides the opportunity to automate maintenance activities.

Advances in modeling and simulation (M\&S) may enable the role of the operator to be shifted from remote task performance to oversight of automated systems. Dynamically updating a plant's digital twin representation through integrating multiple sensor signals will be key to automating complex process tasks. Since complex, highly automated maintenance in high radiation areas has not been proven, adequate demonstration is required to validate its performance.
\end{abstract}

\title{
1. INTRODUCTION
}

This report is a component of the US Department of Energy (DOE) Office of Nuclear Energy's molten salt reactor (MSR) campaign. The report has three primary purposes: (1) to describe the envisioned role and the underlying rationale for automated remote operations and maintenance (O\&M) at future MSRs, (2) to provide a state-of-the-art technology reference for relevant radiation-hardened remote technology, and (3) to recommend future research, development, and demonstration (RD\&D) activities to mature and/or tailor remote, automated O\&M technologies to meet the needs of future MSRs.

The scope of this report is limited to technologies that are generally applicable to the nuclear power aspects of MSRs, particularly in relation to licensed safety, security, and safeguards activities. The report does not address specific issues or technologies for any particular MSR design. Not all of the technologies discussed are anticipated to be deployed in any one specific MSR design. The report does not cover general balance-of-plant or non-nuclear automation issues.

Remote O\&M has always been envisioned as a key technology for MSRs because of the high dose levels within containment. Early MSR concepts located fuel salt adjacent to the reactor vessel, which resulted in extreme in-containment doses. More recent designs include shielding or reflectors either within or near the reactor vessel to lessen containment dose rates, albeit insufficiently for human presence at any time following startup or for solid state electronics for more than brief intervals.

In the first nuclear era, nuclear power plant (NPP) designs placed much less emphasis on minimizing staffing levels. The current staffing levels at existing NPPs is a key element of their higher operating costs as compared to natural gas plants. Today's economic imperatives require applying automation wherever possible to minimize O\&M costs. Additionally, many infrequent maintenance tasks make it difficult to develop and retain high skill levels. Automation and advanced M\&S facilitate for preplanning of complex, infrequent tasks while capturing the original intent of the system designers. The cost of automation has decreased substantially with the advance of digital technology, and the ability to provide $\mathrm{M} \& \mathrm{~S}$ of plant components and environments has increased commensurately.

Remote O\&M for MSRs typically would require detailed physical mock-ups, which have historically been required to plan O\&M activities, to validate tooling, and to train staff to perform tasks. However, advanced M\&S that includes detailed process physics and augmented reality (AR) operator interfaces 
continues to improve as digital technology advances. These digital technologies may have reached a maturity level that will preclude the necessity for integrated physical mock-ups, although specialized physical mock-ups of complex configurations may still be preferred to validate tooling performance. ${ }^{1}$

Today's operator interface paradigm is still based on visually guiding tools to perform each task element. AR offers the possibility to improve on prior art, shifting the operator's role from task performance to oversight of the automated system. To enable this shift, dynamic update of the $3 \mathrm{D}$ model environment is required. The updated model must integrate multiple measurements: multiple camera angles, force feedback from tools, radiation sensors, etc. A planning package for infrequently performed tasks would be integrated into the modeling toolset to support the operator's oversight function. For example, information about the extent of a fuel salt spill, as well as the associated radiation field, could be superimposed into the modeling environment. An operator would provide high-level input guidance to an automated maintenance system and then would oversee its activities rather than directing each specific task. 


\section{BACKGROUND AND HISTORY}

Remote O\&M has long been identified as a key enabling technology for MSRs. The environment near used fuel salt is too radioactive for personnel access, and depending on local shielding, it may be too radioactive for solid state electronics to survive for long periods. Consequently, efficiently and costeffectively performing O\&M tasks in high-radiation environments with remote tooling is a necessary capability for future MSRs. This section describes the progressively increasing capabilities for highradiation tolerant remote O\&M that have been developed over time. The US Atomic Energy Commission (AEC) reviews of MSRs in the 1960s and 70s emphasized the importance of remote O\&M for MSRs:

Maintenance - A Difficult Problem for the [Molten Salt Breeder Reactor] MSBR In the final-analysis, the development of adequate inspection and maintenance techniques and procedures, and hardware for the MSBR hinges ... on the requirement that adequate care be taken during plant design to assure that all systems and components which would require maintenance over the life of the plant are indeed maintainable within the constraints of utility operation. ${ }^{2}$

Remote maintenance of a molten-salt fluid-fuel reactor is required due to the presence of intense gamma radiation in the equipment outside the reactor caused by activation of sodium and fluorine in the salt, the presence of fission products, and activation of the structural material by delayed neutrons in the circulating salt. ${ }^{3}$

\subsection{HISTORIC MOLTEN SALT REACTOR PROGRAM}

Maintenance planning was considered part of the historic molten-salt reactor program as early as the 1950s. The challenges of MSR maintenance were well described in the Fluid Fuel Reactors book produced for the AEC in 1958:

The reliability of equipment for handling radioactive fuel solutions and suspensions is considerably more important in homogeneous than in heterogeneous reactors because the residual radioactivity of such equipment after shutdown of the reactor precludes direct maintenance. The possibility of failures of individual components in a homogeneous reactor, moreover, is considerably increased by the corrosive or erosive nature of the media being handled and the temperature fluctuations encountered during startup and shutdown operations. The technical feasibility of circulating-fuel reactors is so dependent on the behavior and reliability of mechanical components that there is little likelihood that large-scale plants will be built before the performance of each piece of equipment has been adequately demonstrated. In this regard, the development of satisfactory valves, feed pumps, mechanical joints, and remote-maintenance equipment for large-scale plants appears to be most difficult. ${ }^{4}$

Oak Ridge National Laboratory (ORNL) had begun experimental demonstration of remote pump maintenance in support of commercial MSR deployment using hot cell tooling by $1958 .{ }^{5}$ Fixtures were designed and added to a high temperature pump to permit making and breaking all service lines en bloc and replacing the rotor element; all of this was accomplished using a manipulator while observing via a camera with a monitor (see Figure 1). 


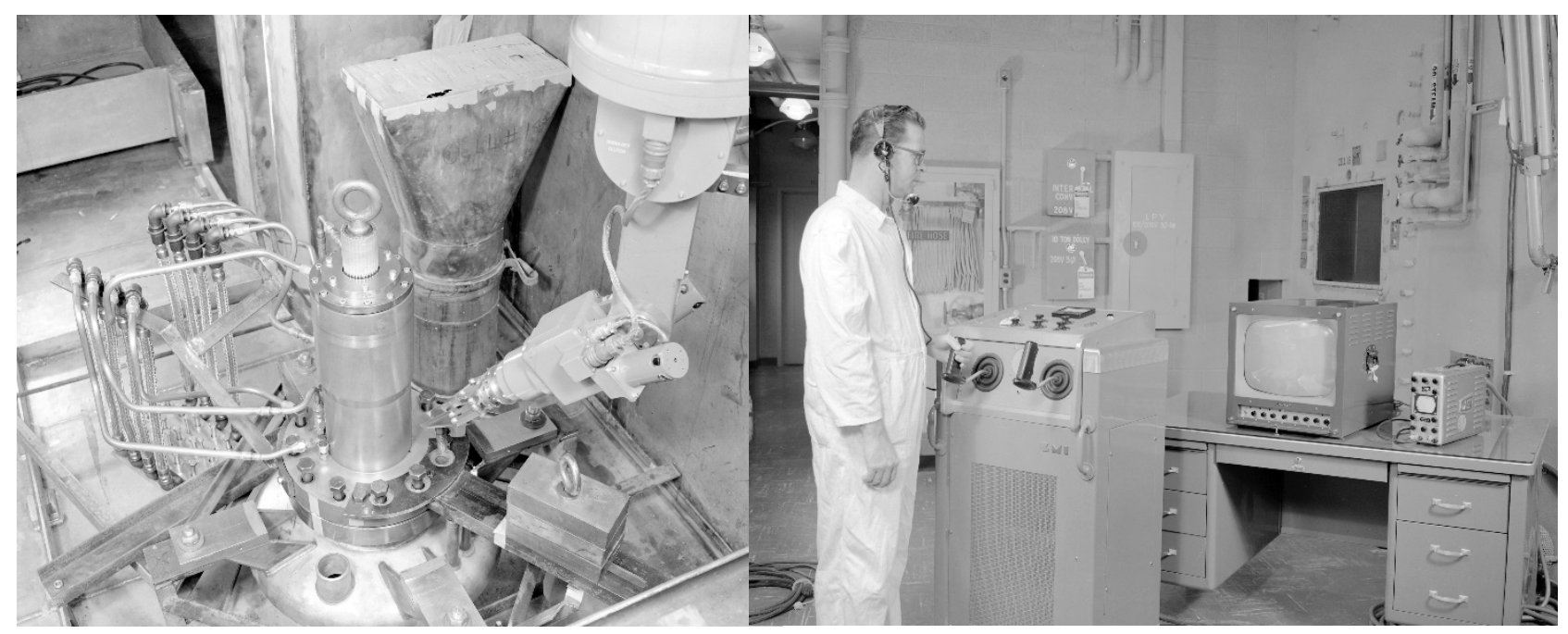

Figure 1. Manipulator arm and pump in hot cell (right) and controlling manipulator via camera and monitor (left) (ORNL photos 42878 and 43068 both from ORNL-CF-58-4-93).

In 1959, ORNL constructed a non-nuclear full-scale physical mock-up of an MSR with prototypic materials and temperatures to develop and demonstrate remote O\&M capabilities (see Figure 2). ${ }^{6,7}$

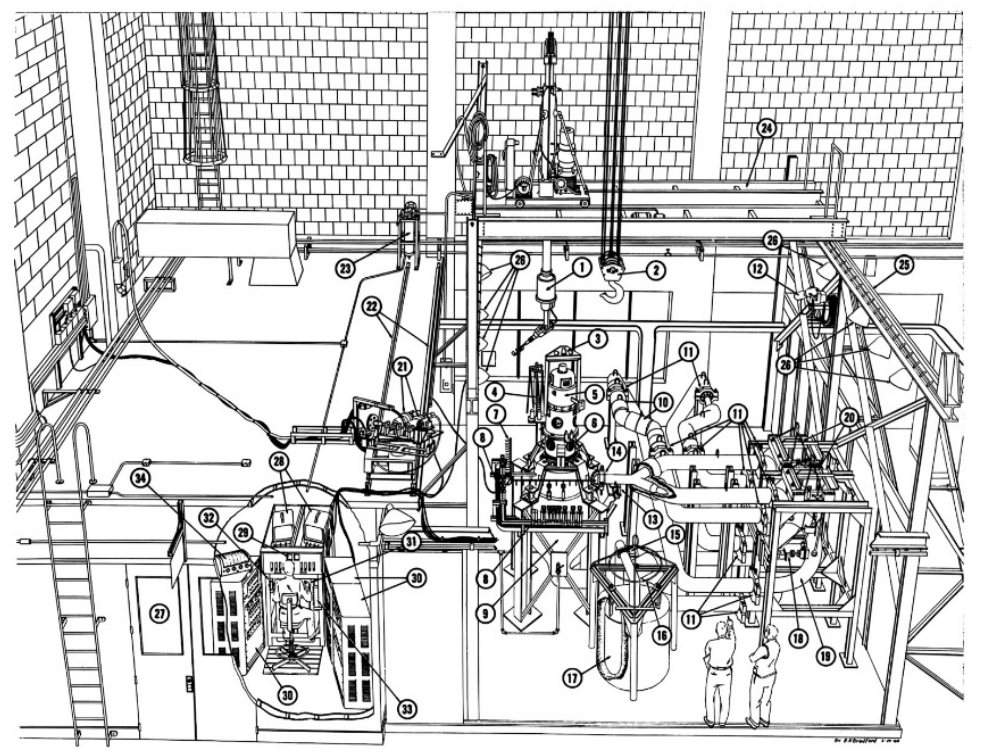

UNCLASSIFIED
ORNL-LR-DWG-46667-A

REMOTE MAINTENANCE DEVELOPMENT FACILITY LEGEND

1. GENERAL MILLS MANIPULATOR
2. OVERHEAD TRAVELING CRANE -5 TON

3. MOTOR LIFTING SLING

4. TOOL RACK

5. D.C. MOTOR - 30 H.P.

6. CENTRIFUGAL SUMP PUMP

7. RACK FOR HEATER AND THERMOCOUPLE DISCONNECTS

8. ELECTRIC HEATER AND THERMOCOUPLE DISCONNECTS

9. REACTOR VESSEL MOCK-UP

10. HEATER-INSULATION UNITS

1. FREEZE FLANGE JOINTS FOR $3 \frac{1}{2}$ in. PIPE (Totol of 16 )

12. TELEVISION CAMERA WITH AUTO-ZOOM LENS

14.

15. FREEZE FLANGE JONTS FOR 6 in. PIPE (Totol of 2)

18. AUXILIARY SCREW JACK FOR HEAT EXCHANGER

19. HEAT EXCHANGER MOCK-UP

20. LIFTING SLINGS AND DOLLIES FOR HEAT EXCHANGERS

21. STEREO TELEVISION CAMERAS

22. TRACK FOR TELEVISION CAMERAS

23. FILTER FOR FREEZE FLANGE AIR COOLING SUPPLY

25. BROCE FOR MANIPLATOR DOLLY

26. CELL LIGHTS

26. CELL LIGHTS

28. STEREO TELEVISION RECEIVERS

29. PRISMS OF STEREO VIEWER

30. TELEVISION CAMERA AND CAMERA DOLLY CONTROLS

31. MANIPULATOR CONSOLE

32. CONTROL VALVE FOR PNEUMATIC TOOLS

33. OVERHEAD CRANE CONTROLS

Figure 2. ORNL Remote Maintenance Demonstration Facility.

The Molten Salt Reactor Experiment (MSRE) is the only MSR that has operated for a significant period. Consequently, its maintenance tooling and procedures provide the only available reference for MSR O\&M. ${ }^{8}$ The maintenance planning for MSRE included construction of detailed $1 / 6$-scale plastic models of the containment structure (see Figure 3 and Figure 4$){ }^{9}$ 


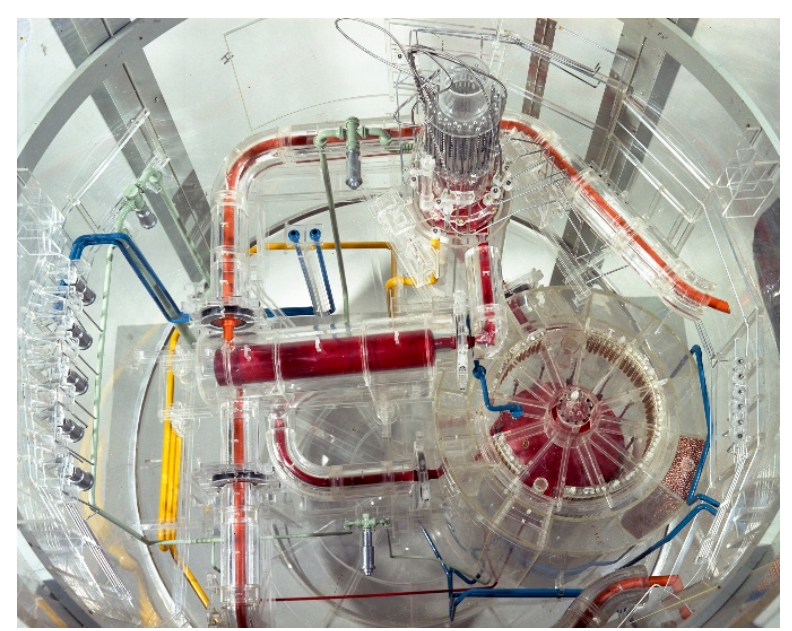

Figure 3. MSRE maintenance planning model (ORNL photo 39417 from ORNL-3419).

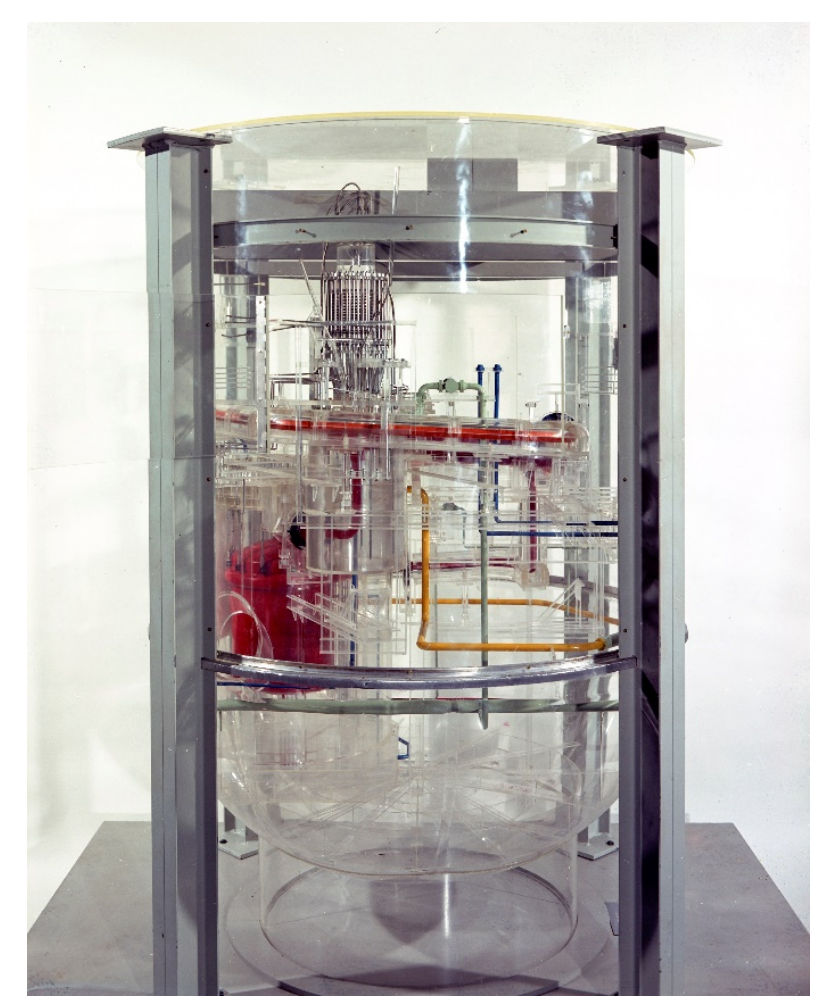

Figure 4. MSRE maintenance planning model (ORNL photo 39416 from ORNL-3419).

Maintenance planning was well underway for MSBR at the time of the program's cancellation. ${ }^{10}$

\subsection{CONSOLIDATED NUCLEAR FUEL PROCESSING}

The Consolidated Fuel Reprocessing Program developed force-reflecting servo manipulators for use in dexterous remote handling, effectively removing the operator from the hazardous environment. The 
decision to move toward force-reflecting arms was based on the nonrepetitive nature of the remote maintenance tasks in an unstructured environment for fuel reprocessing. ORNL developed the first digitally controlled force reflecting servo manipulator (see Figure 5).

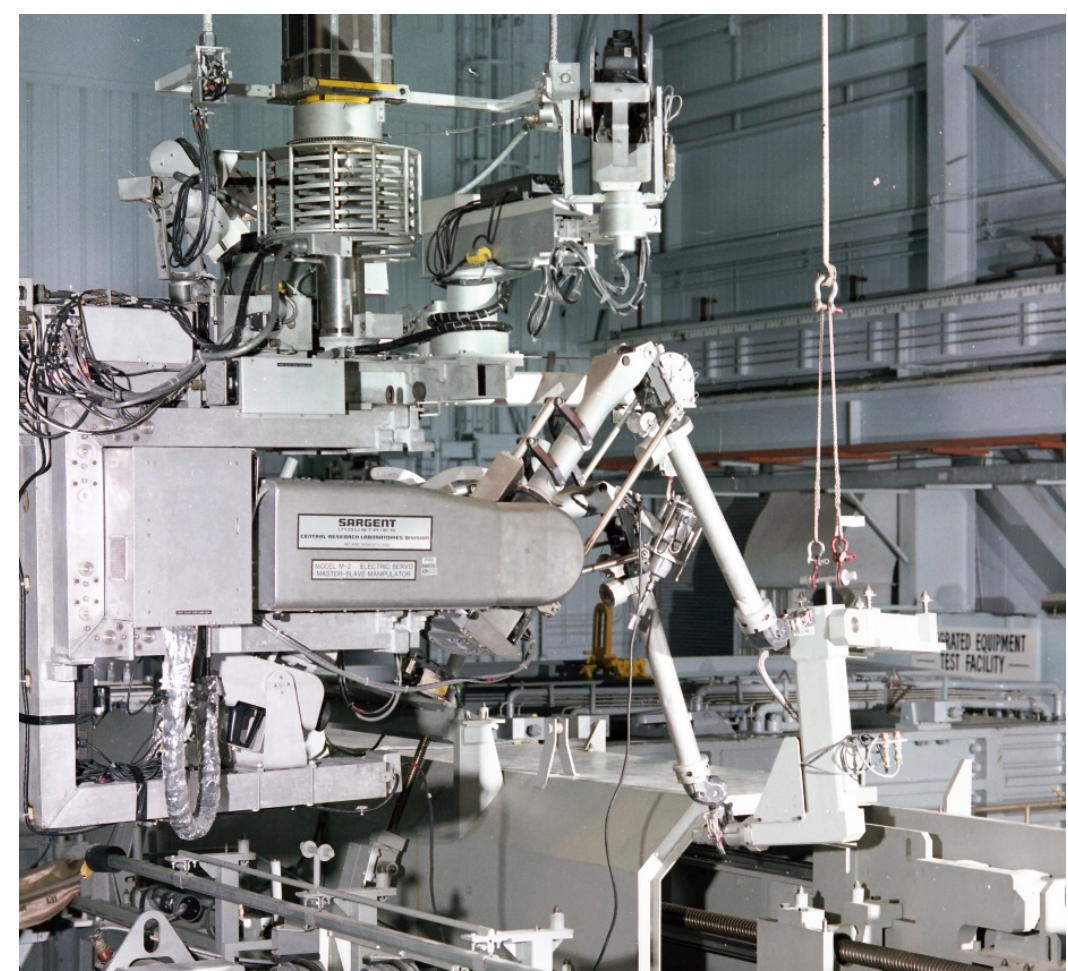

Figure 5. M2 servo manipulator in operation (ORNL photo 01677-86).

The advanced servo manipulator (ASM) (Figure 6) was based on a mechanical drive concept using gears and torque tubes rather than metal tendon (tape) drives. ${ }^{11}$ The gear-driven ASM design is more reliable and is also capable of being remotely maintained. Because the ASM incorporates modular construction, each working module can be replaced by another ASM in situ. 


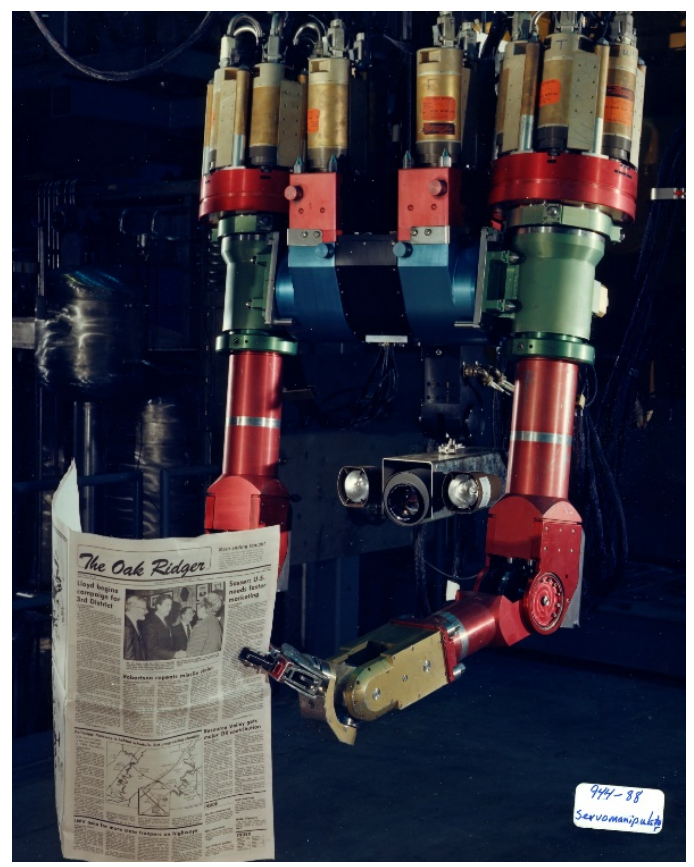

Figure 6. Advanced servo manipulator (ORNL Photo 00944-88).

The ASM arm was designed with the normal elbow position aligned with the lower arm segment. The end effector is capable of an uncoupled roll motion to implement pure rotations for threading, twisting, and other such common tasks. A unique wrist mechanism providing four degrees of freedom was developed for the ASM, providing orthogonal intersecting pitch, yaw, and roll axes. The wrist is back drivable in all axes, including the grip action.

\subsection{SPALLATION NEUTRON SOURCE}

More capable remote O\&M has been implemented in more recent high-radiation environments. Since the Spallation Neutron Source (SNS) mercury target must be replaced periodically due to the intense radiation, hydraulic, and thermal loads, a hot cell was constructed for the periodic replacement and maintenance of the facility. Figure 7 shows the SNS target service bay with master slave manipulators (MSMs) and servo manipulators installed. Welded stainless steel was used for the walls and floors of the hot cell to ensure that they can be cleaned and decontaminated easily. Because unanticipated needs may arise during the life of the facility, additional penetrations from the operator bay into the hot cell were included. 


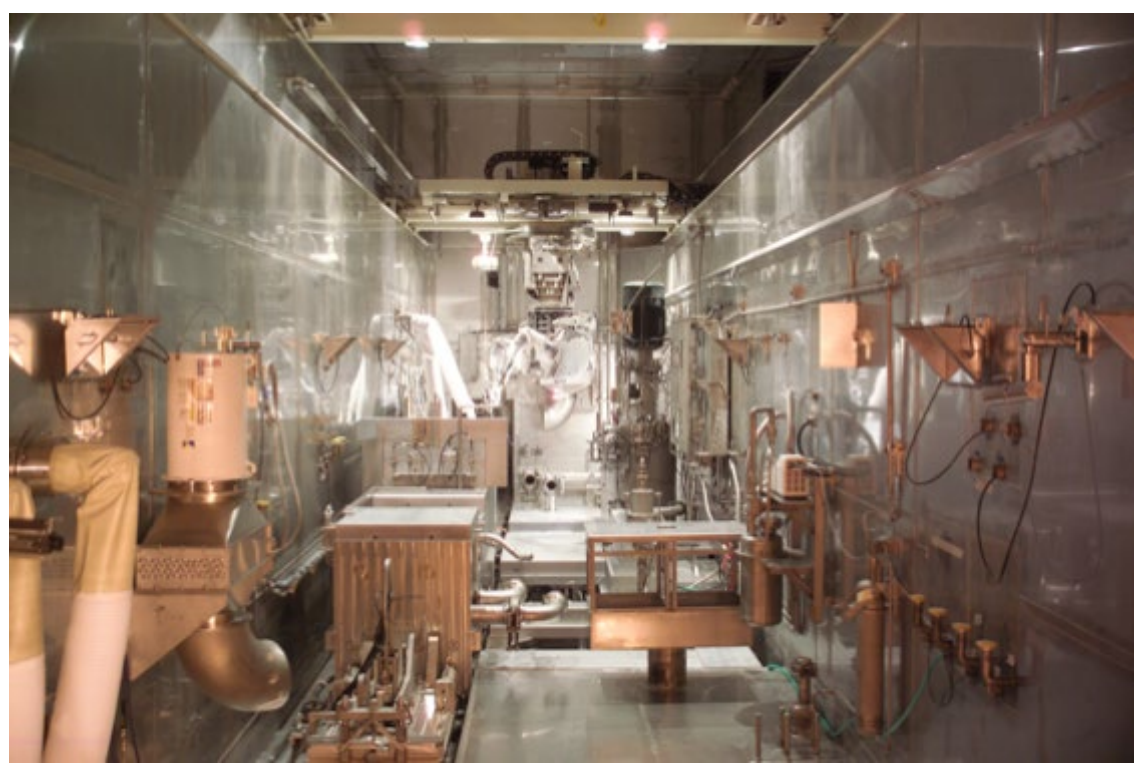

Figure 7. SNS target service bay (ORNL photo: 04118-2005).

The bridge crane that traverses the entire length of the hot cell is used to transfer new targets into position and to place used targets into transfer casks. Once the SNS operation has started, the operator cannot enter the hot cell. Therefore, the shield door is opened to allow the crane to travel into a separate transfer bay provided specifically for crane maintenance. The lower intracell door translates sideways, and the upper intracell door rotates up and out of the way to allow the crane/servo bridges to access the transfer bay. Once the crane is place, the shield doors are closed to minimize radiation. All areas that could have been in contact with contaminated objects in the hot cell are washed down before human entry is allowed into the transfer bay, and hands-on maintenance of the overhead bridge crane is now possible. A top view drawing of the hot cell bridge crane is shown in Figure 8.

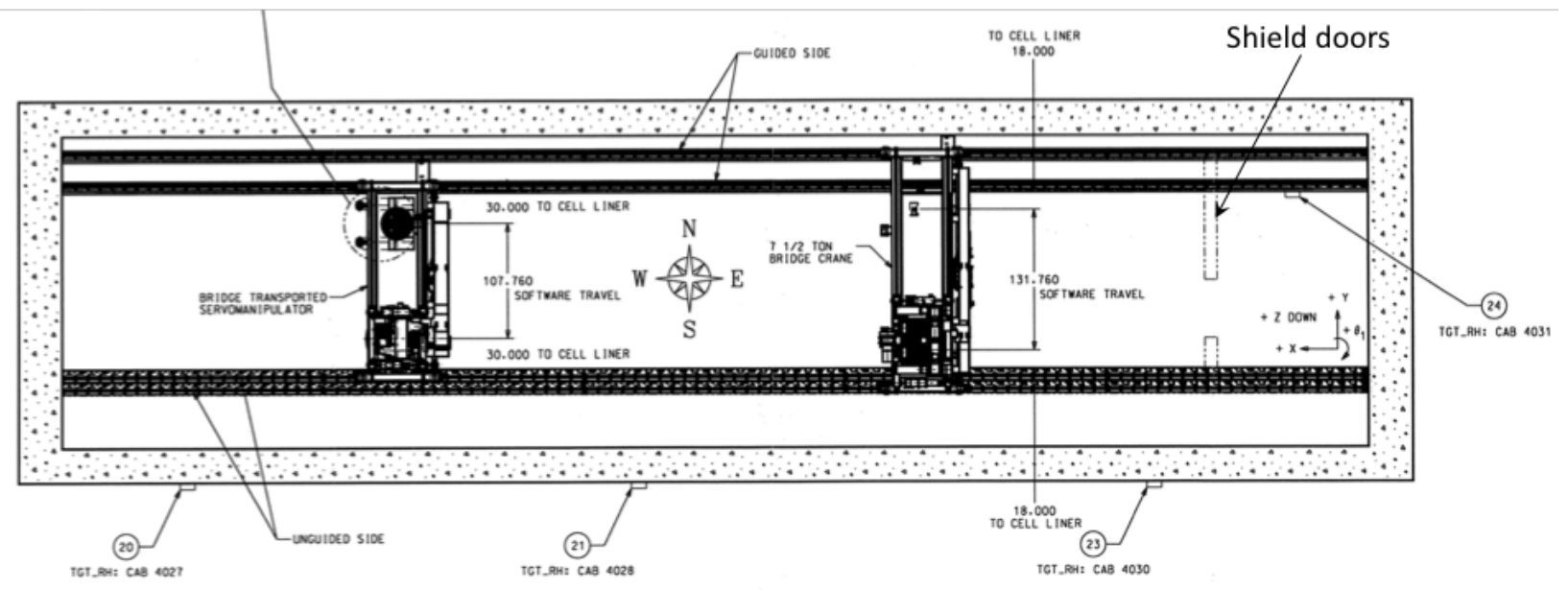

Figure 8. Hot cell bridge crane layout (Drawing No. A-03870929-0). 


\subsection{INTERNATIONAL THERMONUCLEAR EXPERIMENT REACTOR (ITER)}

Planning is currently underway for implementing highly-automated remote handling for ITER's highradiation areas. Remote handling at ITER will use a cask-and-plug remote handling system to ensure the remote transfer of in-vessel components between the vacuum vessel and the hot cell facility for maintenance or disposal. The transfer of components is performed with the help of truck-size double-door containers known as casks. ${ }^{12,13}$ Fifteen casks are on hand to move between the different levels of the Tokamak Building, docking at vacuum vessel ports to collect components in need of repair or replacement and transporting them in sealed containers back to the hot cell facility. The system is challenging to design due to the limited space in the environment of the tokamak, complex trajectories over multiple levels, and a nuclear environment. The heaviest cask, when charged, will weigh 100 tons. 


\section{FUNCTIONAL DECOMPOSITION}

This section provides a high-level overview of nuclear fuel related tasks anticipated to be performed at future MSRs and describes how they may be impacted by automated remote O\&M. While brief descriptions are provided on how tasks will differ between MSR design variants, emphasis is placed on common tasks and systems. The historic MSBR program was based on a thermal spectrum thoriumuranium fuel cycle. For effective breeding, this fuel cycle requires separation of ${ }^{233} \mathrm{~Pa}$ from the fuel stream to allow it to decay in a low neutron flux environment into fissile ${ }^{233} \mathrm{U}$. Some US companies are pursuing commercial development of the $\mathrm{Th} / \mathrm{U}$ fuel cycle. The US DOE MSR campaign does not include support for development of fissile material separation technologies.

MSRs will be required to perform a diverse set of activities over the course of their lifecycles, to include construction, operations, maintenance, inspection, replacement, and decommissioning. Safety, security, and safeguards activities must also be integrated into plant activities throughout its lifecycle. Further, as unplanned events will occur during the plant's lifecycle, the ability to effectively and efficiently respond with minimal disruptions also must be incorporated into the design.

Unlike most elements of MSR technology, the MSRE does not provide a substantial template for automated remote O\&M, as it was not designed for long-term operation, nor was it required to accommodate safeguards or to minimize staffing resources. Consequently, plant designers must draw on examples from other nuclear areas and must consider the planning activities required for the larger MSBR that was intended to be built after the MSRE. ${ }^{14,15,16}$

\subsection{CONSTRUCTION}

The reactor containment will not have high doses or be contaminated prior to its initial operation. To a large extent, automation and remote systems would not be nuclear specific, so they would fall outside the scope of this report. One nuclear aspect of the construction that is relevant to future remote O\&M is to verify that the construction matches the approved design to provide confidence that safeguards measurements will not be bypassed by undisclosed pathways. Once operational, the containment will have a dose rate that is too high for future human access, so the use of remote systems will be required to modify plant configuration. Consequently, observing the actions of the remote systems provides confidence that the plant's configuration has not been altered from the approved design.

\subsection{INITIAL FUELING AND STARTUP}

Fuel salt will need to be melted and added to the fuel salt circuit, and maintenance must be performed above the fuel salt's melting temperature during fueling. Heat will likely be provided by either internal or external electrical heaters. Fuel salt may be added directly to the fuel salt circuit, or it may be added to a drain tank and then transferred into the fuel salt circuit. The plant's refueling apparatus will probably not have the capability to rapidly add large quantities of material to the fuel salt circuit, so dedicated equipment will be necessary for initial fueling. The fuel may be added while the vessel is in an adjacent fuel handling building or after the vessel has been moved into position. The filled vessel weight will likely set the load limit for the in-containment overhead crane.

Once the reactor has begun power operations, the fuel salt will become self-heating, so external fuel salt heaters will no longer be required, even during extended shutdowns. However, external heaters may remain necessary for connected coolant salt loops. Fueling for breeder reactors will involve substantial amounts of fissile material, possibly with high material attractiveness. Consequently, both safeguards and security will need to be enhanced until power operation has begun. Thermal spectrum reactors are likely to be able to rely on lower assay fissile material for startup, thus reducing the material's attractiveness. 


\subsection{NORMAL OPERATIONS AND MAINTENANCE}

This section lists representative remotely controlled tasks that would be performed as part of normal operations at most MSR design variants. The specific set of tasks to be performed and the details of their performance at any MSR will depend substantially on each plant's configuration. Consequently, to remain broadly applicable, the task list is at a high level of abstraction. Some of the tasks will be performed while the reactor remains at power, and others can only be performed during an outage. Not all MSR design variants will perform all of the listed tasks. Tasks performed using the plant's control system are not included in this list.

1. Introducing or removing fuel. MSRs will undergo frequent refueling. A key safety aspect of MSRs is the minimization of the amount of excess reactivity available. Consequently, small quantities of fuel will need to be frequently added (burners) or removed (breeders). Frozen fuel may be transferred into containment in batches using a transfer hatch, with individual aliquots subsequently dissolved/melted into the fuel circuit as needed, or a separate fuel addition/withdrawal line may pass through the containment boundary. In any case, maintaining fissile material accountancy and radionuclide containment will be necessary.

2. Component replacement. Fuel contacting components will wear out. Fuel salt will need to be removed from the worn-out components prior to their disconnection to allow for replacement. One strategy to accomplish this would be to remove the fuel salt from its circuit to a storage tank and then flush the residual salt from the loop prior to disconnecting and replacing the component. Another strategy would be to include as much redundancy as practical in an integral configuration system and to run until the reactor cannot continue to safely operate. Following this, the fuel salt would be allowed to decay in place for several years, after which the entire reactor vessel would be transferred to an adjacent used fuel handling facility where the fuel salt could be transferred.

3. Introducing redox control material into fuel salt. Fission is chemically oxidative. Graphite will be attacked by too strongly reducing salt, and structural materials will be attacked by oxidizing salt. Therefore, graphite-moderated reactors will need to maintain their fuel salt redox within a redox condition band. Fast spectrum reactors need to maintain their salt in a reducing state. Redox control can be accomplished by adding reducing materials to the salt. The reducing material may be incorporated as part of the fuel replacement or as a separate material.

4. Removing fuel salt samples. Measuring the evolution of the fuel salt's composition shows the changes in the salt redox condition, provides a power generation history, and shows changes in the amount of circulating corrosion products.

5. Removing structural material coupons. Material coupons remain the gold standard for assessing the condition of structural materials, and consequently, they predict the materials' remaining useful life. The coupons will need to be exposed to the salt and neutron environment, possibly at representative stress states.

6. Replacing filters and/or traps in the fission and cover gas systems. The headspace above the fuel salt will contain condensable materials (e.g., $\mathrm{ZrF}_{4}$ or $\mathrm{UCl}_{4}$ ), some of which may accumulate sufficiently to form blockages in the gas lines. Clearing the headspace and/or replacing the filters will be important to avoid pressurizing the fuel salt circuit.

7. Replacing filters for nonsoluble fission products. Some fission products will not be soluble in the fuel salt. These materials may plate out or circulate within the salt. If the insoluble materials are allowed to agglomerate into larger particles, they may enable erosion of graphite or the structural alloy. The filters will need to be periodically replaced as they reach capacity. 
8. Instrumentation recalibration and/or replacement. Sensor output will drift in service. The sensors will either need to be recalibrated in place, removed for recalibration, or periodically replaced.

\subsection{ANTICIPATED OPERATIONAL OCCURRENCES}

MSRs do not yet have an established set of licensing basis events. While the details of specific events will be highly dependent on plant design, undesirable events will undoubtedly occur over the lifetime of any plant. The remote O\&M system needs to have the capabilities necessary to safely, efficiently, and effectively respond to drops, spills, leaks, etc. For example, a fuel leak would cause radionuclides to be present beyond one of their containment layers, thus reducing the plant's defense-in-depth. The maintenance system will need to have the capability to clean up the spill so that power production can resume with minimal interruption.

\subsection{INSPECTION AND MONITORING}

The purposes for inspection and monitoring are (1) to ensure that the plant's systems, structures, and components (SSCs) remain capable of performing their functions and (2) to provide the plant operators with indications of the remaining useful SSC life. MSR inspection requirements will differ from those for light water reactors (LWRs) due to the differences in plant characteristics. For example, the first phase of an LWR containment inspection is a pressure strength test (structural integrity test). MSRs are not predisposed to any accidents that could pressurize containment, so they would not have an equivalent inspection requirement. Similarly, the periodic pressure vessel inspection requirement in ASME Boiler and Pressure Vessel Code Section XI is intended to avert rapidly progressing LWR vessel failure, which would be a beyond-design-basis accident, potentially cascading to the release of large quantities of radionuclides into the environment. Vessel failure in an MSR would represent failure of a single independent element of multiple lines of defense-in-depth and would not be anticipated to significantly increase the probability of radionuclide release into the environment. Consequently, MSR vessel inspection requirements would be significantly different from those of LWRs.

Most monitoring functions would be performed by the plant's instrumentation system, with remotely operated inspection systems engaged to acquire additional information once a problem has been identified. A typical collaboration between the monitoring and inspection systems would be in observing and diagnosing the development of leaks in the first containment layer. The MSRE experienced a small break loss of coolant accident (LOCA) in December 1969 when a freeze valve cracked. The LOCA was detected by the presence of fission gases (mostly xenon with some iodine, krypton, and noble metals) within the reactor cell. ${ }^{17}$ The leak was subsequently inspected through a periscope. ${ }^{18}$

Other typical monitoring functions would include:

- Changes in the rate of in-leakage to the reactor cell. The MSRE employed a small $(1 / 4-$ inch diameter) filtered line to maintain a slight negative pressure within the cell containment. Changes in flow rate within this line could indicate increased leakage from outside.

- Increase in fuel salt level and/or decrease in coolant salt level. Evidence of leaks in the primary heat exchanger could be provided by monitoring either the loss of coolant salt or an increase in fuel salt volume.

- Decay heat removal system functionality. The decay heat removal system could be monitored by observing the temperature difference between its hot and cold legs, along with the coolant flow rate.

- Amount of structural material dissolved in fuel salt. Monitoring the composition of the fuel salt provides evidence of the overall progress of corrosion in the fuel salt loop. Changes to the 
expected low, steady amount of dissolved structural material provide evidence of corrosion progressing.

- Vibration / acoustic monitoring. Changes to the system's acoustic characteristics provide evidence of issues such as loose parts or wear/damage to moving parts.

Remote O\&M systems must be flexible enough to respond to anomalies detected by the monitoring system. The procedures for responding to anticipated wear-out type events would be largely automated. However, the response to unanticipated events would be directed by plant staff using remote tooling. The specific license requirements will determine whether plant shut-down will be required to perform maintenance activities.

\subsection{REPLACEMENT}

The combination of high neutron fluence, high temperatures, mechanical stress, and chemical exposure will degrade the materials near the fuel salt. All salt-wetted MSR components are anticipated to require replacement multiple times over the plant's lifetime. The ability to safely and efficiently replace components will be a major design requirement for the remote O\&M system. All items removed from containment will require surveying for fissile material accountancy.

The actions required to replace components depend strongly on the plant's design. Only brief outlines of proposed plant designs have yet been provided publicly. Consequently, the required replacement activities can only be described at a basic functionality level. Integral designs generally allow for replacing the entire fuel salt circuit (reactor vessel) as a whole, whereas loop designs can decouple the components (once drained and flushed) and replace individual components as needed.

Some designs allow for transferring the fuel salt to a storage tank and then flushing the fuel salt loop. Drained and flushed systems enable components to be replaced as soon as the salt has been removed. In designs that do not transfer the fuel salt to another cooled vessel, several years must pass after reactor shutdown before the reactor vessel can be removed, after which decay heat removal for the fuel salt can continue. These designs require a replacement reactor to be available to provide power during the multiyear cooldown, as the initial reactor vessel cannot be disconnected from cooling systems while it contains recently used fuel.

Some of the components that are moved will be large, heavy, and highly radioactive. The specific lift requirements are anticipated to be key elements in the reactor building's structural design, as the crane must be within external containment and must transfer its load to the building foundation. Also, space must be available within containment to allow for removal and storage of any local shielding that must be moved to allow access to reactor components. In all cases, salt and instrumentation lines must be disconnected, components must be lifted out of position and placed into a large transfer hatch/air lock where they would be surveyed for fissile materials. From there, they would either be repackaged into a transfer/storage cask and placed into dry storage or moved to a storage location in an adjacent fuel handling building.

While salt piping can be remotely cut and welded, flanged connections are much simpler and more rapid to disconnect and reconnect. However, only freeze type flanges have previously been used at MSRs. Thawing a freeze flange would inevitably result in spilling a small amount of the frozen salt, which in a fuel circuit would contain radionuclides. Alternate gasketed flanges would likely be useful for fuel salt service, but in addition to salt compatibility requirements, they will have the same sealing issues as all high-temperature flanges, so they will require significant demonstration before being considered mature for fuel salt service. 
Any instruments within containment will require cabling and connectors. Organic insulators are unsuitable for long-term use in MSR containment radiation environments, so ceramic or glass insulation will be required. Cabling affixed to equipment that can be withdrawn from containment using a crane and maintenance manipulators may employ radiation-hardened cables with organic insulators. The containment environment is likely to be electromagnetically noisy due to the pump motors, control drives, etc., so signal cables will require effective shielding. Well-shielded ceramic insulated cables tend to have high capacitance per unit length, which restricts high-frequency signal transmission, and they also have limited mechanical flexibility. The difficulty in connecting to the instruments provides incentive to minimize the length of cables and to hold the number of measurements made within containment to a minimum. Radiation-hardened remotely manipulable cable connections are a mature technology. Since MSR containments need to be leak-tight but are not required to withstand high pressures, vacuum-type bulkhead feedthroughs are anticipated to be used for signal transmission.

If used, fuel salt mechanical filters will need the ability to be replaced as they plug. Replacing a filter from a fuel salt line involves removing the fuel salt from the line, likely by draining or valving, and then disconnecting, removing, and replacing its pipe segment. Used fuel salt filters will be highly radioactive, perhaps to the point that they will require cooled storage. Fuel salt filters are anticipated to be difficult to survey for fissile materials due to their very high gamma emissions.

\subsection{DECOMMISSIONING}

At the end of plant life, the entire structure will need to be disassembled. As all in-containment components are intended to be replaceable using the remote O\&M system, deconstructing the incontainment portion of the plant would be anticipated to be performed using the automated remote O\&M system.

\subsection{SECURITY}

The passive safety characteristics of MSRs strongly impact MSR security requirements. MSRs will require substantial radiation shielding, which will also serve as an access barrier. MSRs will rely on a redundant set of separated, passive, decay heat rejection systems driven by natural circulation. These systems will eliminate most if not all accessible, vulnerable systems, including emergency diesels, grid connections, switchyard, cooling water connection, etc. Furthermore, MSRs will not rely on operator actions to prevent or mitigate accidents, thus reducing the importance of the control room. Remote O\&M will also avoid the need to provide staff emergency egress points.

MSRs will replace salt-wetted components multiple times over the course of the plant's lifetime. Saltwetted components will have substantial amounts of radionuclides, possibly including nontrivial amounts of residual fissile materials being deposited onto their surfaces, thus making them potential sabotage targets. MSRs will include an off-gas system for fission gases to avoid the potential to pressurize the fuel circuit. Fission gases (including high vapor pressure fission products) and their daughter products are the only radiologically significant radionuclides that would transport off site in the event of a containment breach, thus increasing the safety and security significance of the cover gas handling system.

Due to the MSR's limited requirement for external connections for plant safety or radiation shielding, as well as the lack of mechanisms to disperse radionuclides, the security focus is less focused on preventing an adversary from approaching the plant to detecting and monitoring an adversary's approach while notifying local law enforcement for interdiction. Note, the US Nuclear Regulatory Commission (NRC) has recognized that "advanced reactor designs are expected to include attributes that result in smaller and slower releases of fission products following the loss of safety functions. Accordingly, these designs may warrant different physical security requirements commensurate with the risks posed by the technology." 19 
Future MSR plant security systems will have significant remotely operated aspects. Detecting and monitoring the approach of intruders, including drones and/or other remotely operated vehicles, would be a key security system responsibility, as would reducing the potential for insider threat by monitoring staff locations and activities. Some plant safety systems would also perform security functions, such as prevention of opening containment access hatches while the airlocks contain substantial amounts of unshielded radioactivity.

\subsection{SAFEGUARDS}

The purpose of safeguards is to ensure that fissile materials have not been diverted from peaceful uses. Fissile material monitoring/tracking is the basic methodology employed to verify the lack of diversion. Fissile material accountancy at heterogeneous reactors largely consists of identifying and counting discrete items as they enter and leave material balance areas (MBAs). At liquid-fueled MSRs, fissile materials are not contained in discrete units, so item counting is inappropriate. Recent International Atomic Energy Agency (IAEA) documents acknowledge the differences between heterogeneous and homogeneous reactor fuels.

For liquid fueled (e.g. molten salt) reactors, designers should be aware that such reactors cannot be considered item facilities. Beyond pebble bed reactors, which have countable numbers of semi-distinguishable items, more stringent nuclear material accountancy measures will likely be required to verify the quantities, locations and movements of the nuclear material. These measures can include, but are not limited to, fuel flow monitors, seals, video surveillance, the use of sensors to trigger other sensors, more accurate NDA measurements and sampling plans that select additional items for verification. most of this instrumentation does not yet exist and a significant $R \& D$ effort can be expected. ${ }^{20}$

MSRs, however, have some characteristics that make it easier to ensure that fissile materials have not been diverted easier than in heterogeneous systems. Three characteristics that simplify MSR fissile material tracking are:

1. The very high radiation background within containment, preventing human access and plant modifications through means other than remote O\&M tooling, the use and activities of which can be monitored and controlled,

2. Minimal excess reactivity, which makes adding or removing fissile materials immediately apparent in neutron power measurement when coupled with control reactivity monitoring, and

3. The inherent homogenization that occurs upon addition of fuel to the reactor, which prevents employing a separate unaccounted-for stream of fissile material (equivalent of missing rods in a fuel bundle).

Remote visual monitoring of plant components and activities (in particular the remote O\&M system) will continue to be a central aspect of MSR safeguards. The capability to remotely install well-shielded cameras into containment and to subsequently repair and/or replace them will be a required function of the remote O\&M system.

The extreme dose rate throughout containment argues strongly for treating the entire high-dose containment as a single MBA and monitoring what enters and leaves. MSRs will perform as much plant process monitoring as possible in the more benign environment outside of containment due to the 
challenges of making reliable, long-term measurements within containment. Also, many MSR design variants employ an integral primary system configuration that reduces access for process monitoring.

MSRs will have much smaller amounts of materials entering or leaving than bulk facilities (e.g., fuel processing or fabrication facilities). This facilitates the accurate tracking of fissile materials as they enter or leave. MSR containments will typically be closed (except for the primary and decay heat removal flow paths), allowing inspectors to focus on discrete, infrequent removal activities to maintain continuity of knowledge about an MSR's fissile materials.

Due to their small excess reactivity, MSRs will require frequent additions to or removals from the fuel salt. However, fuel material for extended operations may be stored within containment to avoid the need to regularly breach containment for preplanned fuel additions. Removed fuel will be highly radioactive, which will provide strong incentive not to remove it from inside of containment.

MSRs will have signals indicating the status of fissile materials within containment. For example, exvessel used fuel, which would be anticipated in breeder reactors, will require decay heat rejection. Monitoring the thermal balance of the used fuel decay heat rejection system provides confidence that material has not been removed. Also, adding or removing fissile materials from the reactor will impact the reactor's neutron power when coupled with the compensatory control element position monitoring.

MSRs will require high-accuracy fissile material survey of all materials leaving or entering containment. One key complicating factor at MSRs is the difficulty in assessing the quantity of fissile materials on or within objects in the presence of potentially large quantities of activation and fission products, which is sufficient to make almost all emerging materials be managed by remote handling only. Active neutron interrogation appears likely to be a preferred method for fissile material survey prior to material packaging into casks for transport. Integrating active neutron interrogation into the containment airlock system along with the waste packaging and remote handling systems appears likely to be a necessary part of the plant's design and design evaluation process.

The joint use of signals from the O\&M system is a key issue that remains to be resolved if the activities of the remote O\&M system are to be relied upon to verify the lack of plant modifications and the proper installation of monitoring equipment. The underlying challenge is that plant owners may object to sharing detailed plant operational data, which they regard as business sensitive, with IAEA inspectors. On the other hand, IAEA inspectors require confidence that the signals that they rely upon to make a compliance determination are both adequate and authentic. A number of technical measures are possible to authenticate signals and to limit the amount of data collected. However, signal authentication is a broad subject area beyond the scope of this report, and a determination of what information is business sensitive is plant specific. 


\section{REMOTE O\&M IMPLICATIONS FOR PLANT LAYOUT}

The requirement to have all SSCs within containment accessible to the remote maintenance system has significant implications for plant design. No commercial-scale MSR has ever been built, so maintenance system design evaluation cannot be based on direct experience. Plant layouts for different proposed designs will have substantial differences. Some integral designs have indicated that their intention is to remove the entire reactor vessel, including fuel salt, as a single component, while other designs call for draining the fuel salt and flushing the interior surfaces of the fuel circuit prior to disconnecting components for replacement.

The MSBR plant is the only public design concept that includes significant considerations of maintenance and repair. ${ }^{21}$ However, MSBR did not incorporate several modern considerations:

- The salt-wetted components (reactor vessel, pump shell, heat exchanger shell, and piping) were considered to be permanent structures not intended for replacement. Nearly all modern designs allow for replacing salt-wetted components, perhaps multiple times, over the course of the plant's lifetime.

- The system was configured as a loop design. Most modern MSR designs employ an integral or quasi-integral (reactor core and heat exchangers within a secondary vessel) configuration.

- Decay heat removal requires draining the salt into a storage tank via a freeze valve. Some modern designs employ a drain tank, with the remainder employing natural circulation decay heat removal from fuel salt while it remains in the reactor vessel.

- The plant layout does not incorporate fissile material tracking.

- The containment outer shell is not designed to withstand aircraft impact and was envisioned to be almost entirely above grade.

- Many in-containment maintenance activities were intended to be performed directly by staff members using long handled tooling through a maintenance shield. Today's designs would employ much more automation and would be overseen by plant staff members from a control room environment.

The level of contamination control required during maintenance activities is a key design issue. Maintenance activities will likely include recovery from anticipated accidents such as fuel salt spills and/or leaks. If fuel salt has leaked, it may have contaminated, friable insulation. Recovery from more serious spills may also require removing solidified fuel salt from either the interior surface of a guard vessel or the catch basin on a containment floor. Any direct manipulation of fuel salt is likely to result in mobile contamination, thus necessitating leak-tight barriers.

All MSRs will require substantial amounts of shielding of the fuel salt and off-gas systems. The shielding can be local to the component, part of the containment structure, or some combination of both. All of the fuel-salt-wetted components will be highly radioactive from deposited radionuclides and activation of the structural materials. The cover gas handling system will also be highly radioactive. Consequently, the remote O\&M system will need to be able to manipulate highly radioactive components. Exterior local shielding will need to be removed and stored to enable manipulators to access the components.

Modern MSR designs will have substantial layout differences based on the specific requirements of specific designs. General information about MSR plant layout can be derived from the MSBR design, which called for a high bay with floor shielding above a reactor cell. Floor shielding blocks would be removed using an overhead crane to enable installation of a maintenance shield above components as needed for off-line maintenance. Shielded transfer casks could be placed above the maintenance shield, and worn-out components would be lifted into the casks using an overhead crane. The MSBR's high bay floor was intended to enable human access to perform most maintenance tasks. This type of floor 
structure is unlikely to be used in future plants, as humans will likely be in a more supervisory role over automated or remotely controlled equipment rather than directly performing tasks. Instead, the shielding is likely to be divided between (1) local shielding within and around the reactor vessel (to extend the vessel's lifetime and improve the neutron economy), (2) cover gas systems and other radionuclide containing systems, and (3) exterior shielding that serves an additional purpose of absorbing external impacts. Future MSRs are likely to be deployed either partially or fully below grade and would incorporate impact absorbing materials as their outer shielding/protective layer (earthen berm).

The combination of (1) a lack of need to provide multiple staff emergency exit points, (2) the requirement to assay all materials that exit containment for their fissile content, and (3) the infrequent requirement to remove large, heavy, highly radioactive, heavily contaminated materials from containment all mediate for employing a single large airlock-type transfer mechanism out of containment. An overhead crane would be used to lift materials within containment, along with radiation hardened servo manipulators to perform maintenance tasks. Nearly all prior high-radiation maintenance / mechanical manipulation designs have used some variant of overhead cranes and manipulators. Both ITER ${ }^{22,23}$ and the SNS ${ }^{24}$ maintenance facilities are modern examples of overhead manipulator configurations under extreme radiation conditions. The crane and other maintenance equipment would be withdrawn to a low radiation environment during at-power operations where the maintenance components themselves could undergo maintenance. Well-shielded cameras would remain within containment to provide assurance that fissile materials have not been diverted.

An MSR's containment may be subdivided into a number of separate containments - reactor vessel, drain tank, flush tank, cover gas - to minimize the spread of contamination in the event of an accident and the source term available for release for more severe accidents. This configuration would be similar to the multiple bays employed in a hot cell facility. Alternatively, the individual systems may employ local shielding but remain connected for ease of maintenance access. Local shielding will absorb substantial amounts of energy and may require cooling during operation. An aggravating factor in MSRE's maximum credible accident ${ }^{25}$ was water that leaked into the reactor cell and contacted the fuel salt. Future MSR designs will likely avoid the presence of significant quantities of water in or near containment to avoid the potential for over pressurizing containment. Consequently, shield and component cooling are likely to be accomplished by chilled atmosphere circulation. Heating the containment atmosphere by fuel salt following a large break LOCA would increase the containment pressure. In such a case, the excess pressure could be allowed to vent through the cover gas handling system, or the exterior shielding could be designed to provide heat transfer from the containment atmosphere to the exterior environment.

Power and signal cables must be routed through the shielding and containment boundary to a benign environment. Cable replacement has been among the most expensive elements of existing light-watercooled reactor life extension. Ceramic/glass insulated cables contained within metal sheathing would have very long lifetimes under MSR service conditions and are not combustible. As MSR containment will have only a small pressure differential, commercial vacuum pressure bulkheads are anticipated to be adequate for cable penetrations.

Different MSR designs may have different radioactive waste, fuel storage, and fuel treatment configurations. In breeder designs, small quantities of used fuel must be removed from the reactor relatively frequently, perhaps daily, and the used fuel requires cooling for several years. The removed fuel's fissile materials also require tracking. If the used fuel is retained within primary containment, then relatively simple thermal and mass tracking can provide assurance that its fissile materials have not been removed. Once a useful quantity of used fuel is available that no longer requires forced cooling, its container can be sealed and transferred out of containment via the airlock, where it would be subject to more detailed fissile material assay and overpacking. Breeder designs also require the addition of new unenriched fuel and redox control materials. Premeasured aliquots of fuel/redox control materials are 
likely to be introduced into containment in batches and added to the fuel circuit as needed using remotely controlled or automated equipment.

In burner designs, small quantities of fuel must be added to the fuel salt relatively frequently, perhaps daily. Used fuel can either be left within the fuel circuit, thus increasing its volume, or it can be removed for storage. Used fuel will require cooling for several years. Cooling may be performed within containment, thus allowing removed fuel to accumulate into batches before it is removed, or individual aliquots may be removed from containment. In either case, the used fuel container would be sealed and transferred out of containment via the airlock, where it would be subject to more detailed fissile material assay and overpacking and then transferred to a used fuel storage facility.

Future MSRs will require local storage facilities for replaced components and structures. As the materials will be activated and will have surface contamination, they will be transferred out of containment in shielded transfer casks and placed into shielded storage. Materials that require cooling such as used fuel will initially be moved to a cooling pool and eventually to dry storage. Materials that do not require cooling can be directly emplaced in shielded storage such as shallow wells/pits to decay. 


\section{REMOTE O\&M TECHNOLOGY OVERVIEW AND MATURITY ASSESSMENT}

\subsection{MECHANICAL CONCEPTS}

The main additional design criterion for mechanical components in radiation environments is to include remote maintenance in the equipment design. Remote maintenance or replacement typically requires considerably more time than hands-on maintenance. Downtime encountered during repair/maintenance can be reduced by optimizing the interfaces with the maintenance system. Using maintenance manipulators with good dexterity, maneuverability, and force reflection can greatly reduce maintenance time. It is also important to design the equipment to be as modular as possible to enable efficiently swapping out components that need replacement.

\subsubsection{End Effectors}

End effectors for most manipulators are parallel jaw-type clamps, so the equipment interface needs to be modified to enable a parallel jaw to effectively hold the tool/equipment while performing the task. Figure 9 shows an impact wrench that has been modified for use with a parallel jaw end effector.

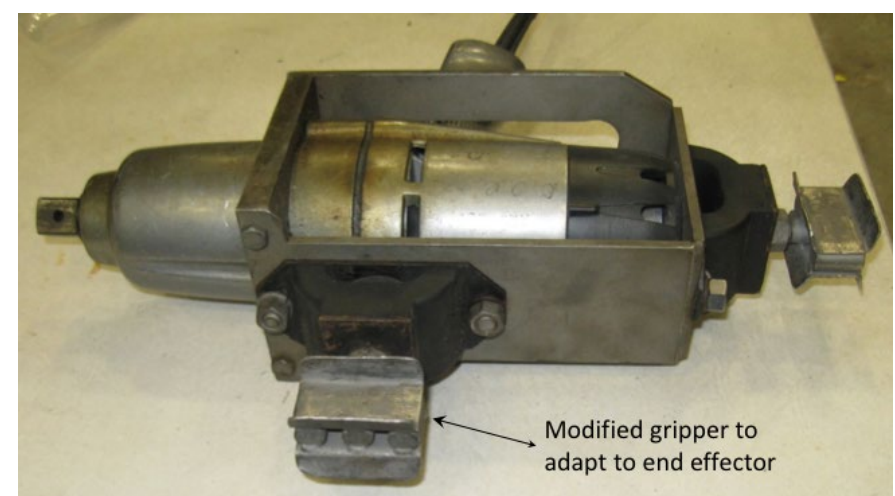

Figure 9. Modified impact wrench (photograph taken by author).

\subsubsection{Cranes}

Cranes are important parts in hot cell design for placing large components during assembly and disassembly. High radiation area cranes require several modifications from off-the-shelf models since perform hands-on maintenance is not possible inside the hot cell. At least the main drive motor should be redundant to minimize the potential for the crane stopping in the hot cell. The crane must be able to be moved to a low radiation area for hands-on maintenance, and a designated area for wash down of possible contamination is needed. Shield doors between the high and low radiation areas are also needed, as well as high radiation-tolerant grease, a modular design for easy replacement of parts and modification of hooks and tooling.

\subsubsection{Transport Casks}

Transport casks provide shielding of highly radioactive equipment or materials. The most important aspect of cask design is its shielding and securement of the material being transported. Cask are for waste handling or transfer of radioactive material from one facility to another. An example of a used nuclear fuel cask being unloaded at ORNL is shown in Figure 10. MSR transport cask technical requirements will largely be similar to those of other nuclear sites. Accidents involving dropped or improperly sealed casks must be considered in the suite of plant licensing events. 


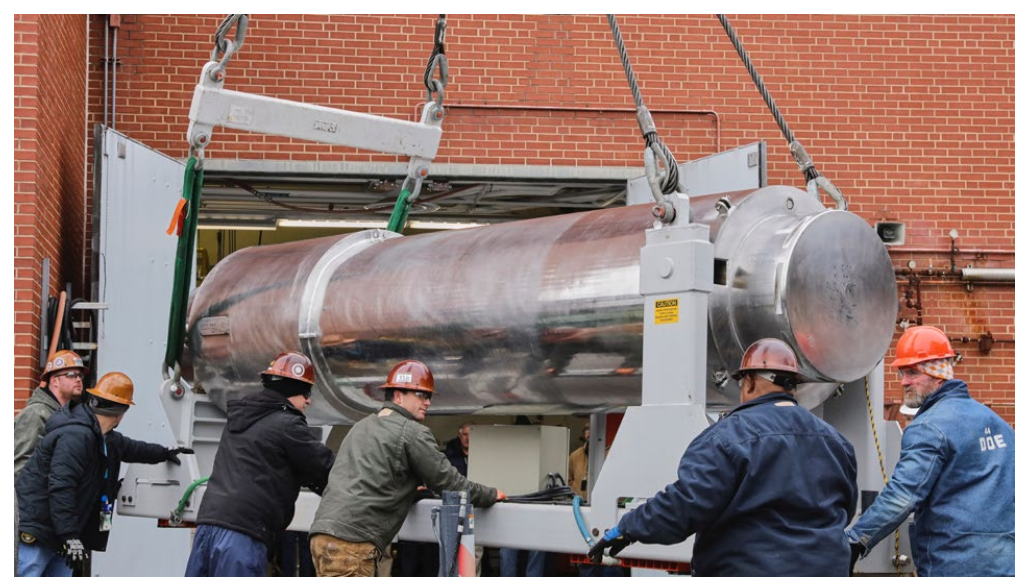

Figure 10. Used nuclear fuel cask at ORNL

(ORNL photo 2016-P00292).

\subsubsection{Linkages}

A general design guideline for a radiation environment is to minimize the number of moving parts. Each joint is another point for potential failure. Rather than have multi-degree-of-freedom sophisticated manipulators, it is better to have the fewest possible number of degrees of freedom to perform the job.

\subsubsection{Power Transmission Options (Electrical, Pneumatic, Hydraulic)}

Electric motors are by far the most common power transmission option in a radiation setting. Electrical windings can withstand $2 \mathrm{MGy}$, and as long as all the electronics controls are removed, they work well in these types of radiation environments. For position feedback, resolvers have proven more reliable than encoders (which have solid state electronics) in radiation environments and where vibration is present. ${ }^{26}$

Pneumatic actuators work well if precise position control is not required. Since the gas released from an actuator goes into the hot cell atmosphere, leakage is generally not an issue. Pneumatics can provide higher power output than electric motors with a lighter and smaller form factor.

As a general rule, hydraulic devices are not used in radiation environments since hydraulic fluid leakage is nearly always a concern. Also, most hydraulic fluids are organic and will be damaged by the radiation. Simple fluids with very high radiation tolerance such as water or glycol can be used as a motive fluid, but the design will need to account for possible corrosion from these fluids, as well as the potential for pressurizing containment from flashing them into vapor.

\subsubsection{Force Feedback via Power Signature}

Force feedback allows the operator to get a sense of the task being performed. Without force feedback, operators can easily bend or break parts during assembly. During part mating, force information is used to improve part alignment. The force provided by a motor is proportional to its current draw. Most force feedback measurements employ a current loop that is directly correlated to the torque being applied by the servo motors. When the manipulator is in contact with an object in a hot cell, current is increased to the motor to provide force. The amount of current required for motion provides force feedback for the operator. Alternatively, a force/torque sensor could be applied at the end effector to obtain force and torque information, but its performance is generally not as intuitive for the operator as the current feedback approach. 


\subsubsection{Cutting/Welding}

Cutting is an easier option than welding in a hot cell, and it can be accomplished with various electrical tools adapted for hot cell operation. Welding is more complicated due to the precise tool position that needs to be maintained. Also, since an oxide layer forms on common structural metals after operation in hot oxygen environments, if a portion of the pipe has to be cut and welded, then the oxide layer needs to be removed. Accomplishing this in a remote environment is challenging, and care must be taken to anticipate cases in which welding has to be performed. Additionally, radiation damage (principally helium build-up from neutron interactions) to the base material can prevent successful rewelding. ${ }^{27}$

\subsubsection{Flanges and Gaskets}

Flanges and gaskets for piping in a radiation environment should be selected for remote operation. Both Reflange, and Graylock provide commercially available flanges for remote operation whereby one single actuation brings the clam-shell flange connection together. The flange gaskets can be modified to clip on for easy installation. Figure 11 shows a remotely operated flange.

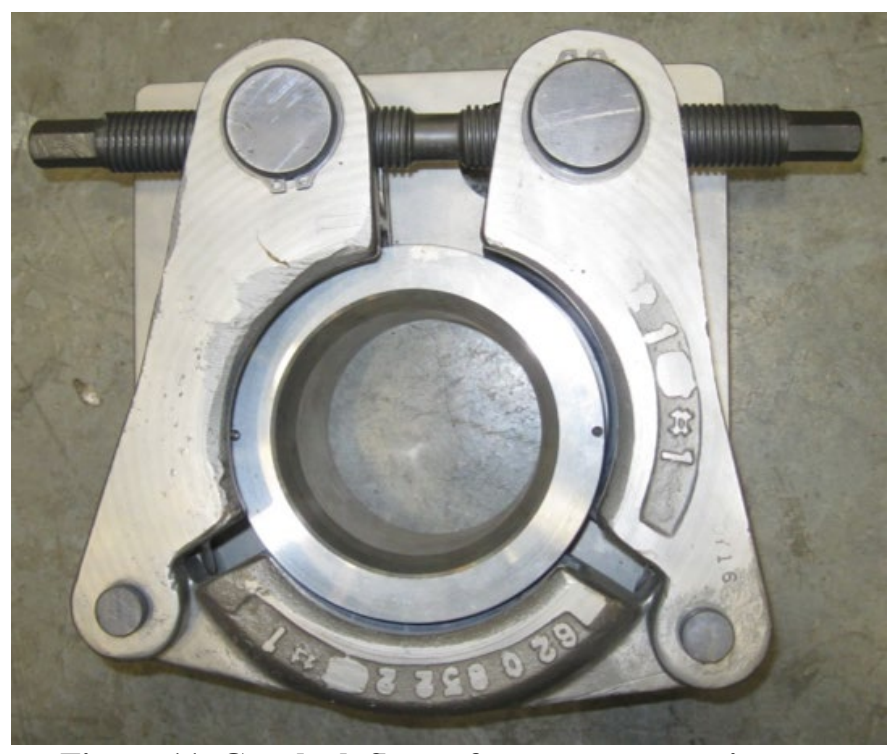

Figure 11. Graylock flange for remote operation (photograph taken by author).

\subsection{SENSORS AND ELECTRONICS}

\subsubsection{Radiation Hardened Cameras}

\subsubsection{Background}

Because video cameras have been available for use since the early part of the $20^{\text {th }}$ century, a variety of camera sensors are available, all of which are based on one of two primary methods of transduction. The first and oldest is the cathode ray tube (CRT) scanning approach to image capture. A variety of techniques and tube types are in this category, but they all include a beam of electrons scanning an image plate to sense varying degrees of intensity. From that scan, an image is electronically reconstructed. The various types (image orthicons, vidicons, and others) are typically differentiated by the technique they use for reading out the imaging plate. The plates may be either photosensitive or charge based, depending on the type of light sensing and readout structure used. Figure 12 illustrates an image orthicon tube which was used extensively in the middle of the last century. 


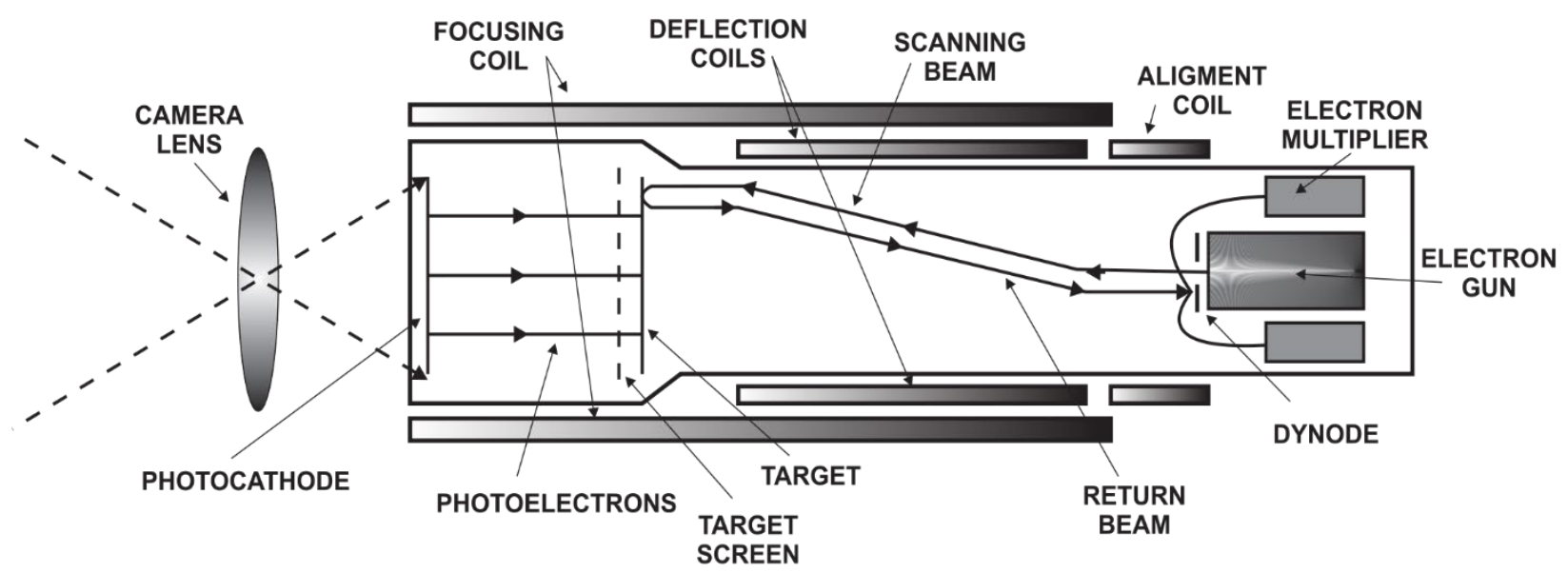

Figure 12. Image of orthicon tub cross section schematic.

The most recent advancement since the 1980s is the use of solid-state light sensors such as chargecoupled devices (CCDs) or complementary metal oxide semiconductor (CMOS) active pixel sensors (APSs). These sensors are fabricated in solid-state processes, usually silicon, and they use the photosensitivity of silicon or other semiconductors. The CMOS sensors are as ubiquitous as cellphone cameras because of their low power requirements.

\subsubsection{Applicability}

Most cameras presently used for extremely high total dose applications are CRT-based because of the naturally high threshold of radiation tolerance of vacuum electronics. ${ }^{28}$ Vacuum tube cameras are made primarily of glass and metal, but they require a photosensitive element to function, and the choice of this element determines the overall hardness of the camera. Solid-state cameras have the advantage of better resolution and power requirements than CRTs, but since the fundamental operation depends upon the charge generated in a semiconductor, current solid-state cameras are not usually rad hard. Even when they have been hardened, they tend to have dose capabilities that are 2-3 orders of magnitude lower than CRTbased cameras.

With that said, there is an active area of ongoing development to take advantage of the newer smallfeature size CMOS semiconductor processes with inherent radiation hardness. Much of this activity is being driven by the need to create cameras for remote handling operations at ITER and other such applications. The goal is to create cameras that are hard to at least $1 \mathrm{Grad}$ (10 MGy), and based on current publications, it appears that cameras suitable for extremely high total integrated dose (TID) applications will be available soon. ${ }^{29,30}$

\subsubsection{Manufacturers}

CRT-based cameras specifically designed for high-rad environments are available from several vendors. The most hardened devices are monochrome cameras manufactured by Mirion Technologies, LightsCamera-Action, and Diakont. The Mirion model R941 camera can withstand 2 MGy total dose with an exposure rate of $>30 \mathrm{kGy} /$ hour using a vidicon tube. For improved light sensitivity, the camera is available with a chalnicon photoconductive layer but at a reduced total dose. The Lights-Camera-Action RH-300 can also survive 2 MGy, as can the Diakont D40 system. All these devices are supplied with nonbrowning lenses. There are also reduced hardness versions from these vendors and others, as well as color versions featuring reduced dose capability. 
Because of the variety of non-browning zoom lenses offered as both built-in (Mirion, Lights-CameraAction) and replaceable (Diakont), almost any visualization application for maintenance should be possible. Most of the cameras described here are of similar size and could be considered for single view, group view (clustered around a workspace), or even stereoscopic view using two co-located cameras and virtual reality (VR) goggles. This might be particularly useful for activities requiring fine motor skill work.

\subsubsection{Cables and Interconnections}

\subsubsection{Background}

Cables are required to connect electrical components within a system, and since some of those components are likely to be within a high-radiation zone, they will themselves be exposed over some amount of their length to the same field as the components. Cables not only carry signals to and from the target components, but they also carry power. This requires a sufficiently large conductor so as not to incur a large voltage drop on a long (up to hundreds of feet) cable, but not so large as to make bending the cable around within the system difficult.

Most cables of interest will consist of multiple conductors and will require insulators around the conductors. The insulation stability is important because of the nature of signal propagation. Coaxial camera cables normally exhibit a 75-ohm characteristic impedance, which is an industry standard for closed-circuit television (CCTV) transmission. The characteristic impedance depends on the dielectric constant, the insulation resistance, and the dimensional stability of the insulator. Any changes in these factors as a function of radiation or temperature will negatively affect the fidelity of the signals carried by the cable. Static control signals and power are not as dependent on the cable characteristics, but they require a high degree of stability to ensure that crosstalk, current leakage, or even cable failure does not occur.

Among the highest dose-rated materials offered commercially for flexible cable are thermoplastic polyimide (TPI) and polyimide, either of which can survive greater than $100 \mathrm{MGy} .{ }^{31}$ If operated in an inert atmosphere of nitrogen or in a vacuum, they can survive in excess of $500 \mathrm{MGy}$. There is a continuum of other available materials exhibiting less hardness, so there are many options of cabling to meet most needs. Moreover, these materials can withstand high temperatures $\left(>200^{\circ} \mathrm{C}\right)$ and are halogen free.

Nonflexible cables are preferred for permanent installations that will not require movement since they can be more rugged and immune to flexural damage. Mineral-insulated (MI) cables are usually preferred since they have been tested for decades. MI cables are typically made of conductor rods in a sheath and then filled with $\mathrm{Al}_{2} \mathrm{O}_{3}$ or $\mathrm{MgO}$. They are well suited for nuclear plant installations since they are typically radiation hard and fire rated and have been used even in reactor core applications. $\mathrm{MgO}$ is known to survive with only mild damage in environments up to $10^{8}$ Gy gammas and $10^{18} \mathrm{n} / \mathrm{cm}^{2} .{ }^{32}$ One issue with $\mathrm{MgO}$ that would only affect cables carrying very small signals ( $\mathrm{nA}$ or $\mathrm{uV}$ ) is the radiation-induced electromotive force effect (RIEMF), which is the generation of spurious signals due to gamma and neutron interaction with $\mathrm{MgO}$ dielectric. RIEMF is covered in some detail in Vermeeren and Van Nieuwenhove ${ }^{33}$ and the references contained therein.

The connectors used for cabling to and from the various instruments are just as critical as the cable to which they are attached. Many multi-conductor cables will be terminated by multi-pin connectors. The pins on the connectors, as shown in Figure 13, mate to sockets on matching connectors. Since these are mechanical connections, there is always a concern for failure. The connector is also designed to mimic the cable impedance by placing the mating pins or sockets in an insulating holder. The integrity of the 
insulation of this part is just as important as the cable itself. The connectors must be chosen to be easily manipulated robotically if they will be replaced remotely without direct human contact.

\subsubsection{Manufacturers}

There are several manufacturers of flexible cable offering options that can well exceed the very high total doses that the cameras can withstand. Axon Cable sells a variety of single wires and multi-pair cables available in a variety of insulation types. Mirion sells the R90 series of cables designed to interface with their cameras that will withstand 1 MGy. Habia Cable also manufactures a variety of coaxial cables that can survive high temperatures and are tolerant to at least $1 \mathrm{MGy}$.

Rigid cables such as MI cables are manufactured by a variety of companies, most of which seem to have experience with nuclear reactor applications. Omega Engineering (Omega.com), Ari Industries (ariindustries.biz), and Techno Instruments (http://www.techno-instruments.com) are just a few.

From the connector standpoint (see Figure 13), TE Connectivity (Deutsch) manufactures a variety of multi-contact connectors that are able to withstand anywhere from 0.2 to $2 \mathrm{MGy}$. Other manufacturers are LEMO and NAMCO.

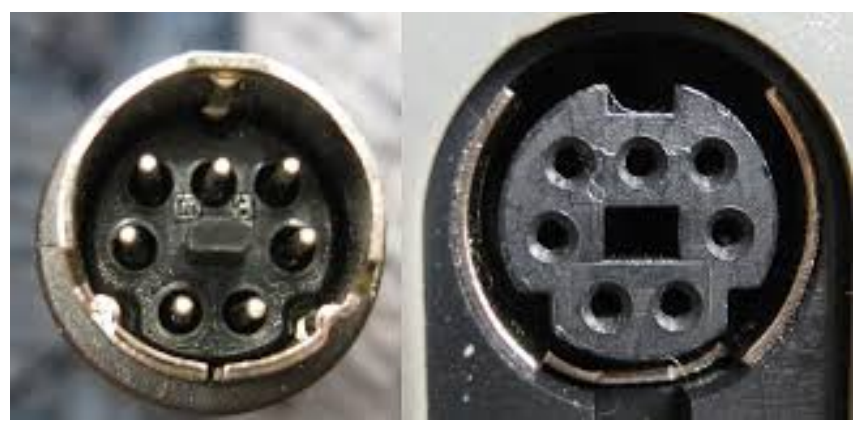

Figure 13. Radiation hardened cable connectors.

\subsubsection{Fissile Material Survey Sensors}

As described in Section 3.6, all salt-wetted MSR components are anticipated to require replacement multiple times over the lifetime of the plant. As such, all components (items) removed from containment will require fissile material surveys for nuclear material accountancy. For example, if a heat exchanger is replaced, there will likely be residual fuel salt, and thus fissile material, within the old heat exchanger.

Fissile material on or within components will require measurement in the presence of potentially large quantities of fission products. Not only will this result in the need for remote handling of emerging components, but it will also make direct gamma-ray nondestructive assay (NDA) measurements of fissile materials challenging. This is due to the anticipated high-background of fission product gamma rays that would result in overwhelming signal, in addition to many interferences in the gamma-ray spectrum. Bulk components are likely to provide high shielding; therefore attenuation of gamma rays of interest for conducting fissile material surveys could limit accuracy of inaccessible regions. If the surfaces of the item are not accessible for a gamma survey or if large self-attenuating deposits are expected, then material distribution can be determined by neutron counting using an array of neutron detectors surrounding the sample and by possible rotation of the item. 
The method of calibrating gamma measurements to the known source term (fuel salt) could be used to perform fissile material surveys. If the fuel salt that the item was in is accessible, it can be sampled to obtain a simple signature such as gamma dose rate or ${ }^{137} \mathrm{Cs}$ intensity (662 keV peak). This in turn can be related to fissile content e.g., dose-to-gram conversion, and then a gamma survey can be used to provide the holdup estimate. However, this method is challenged by the presence of substantial attenuation. Modeling can be used to estimate corrections, but this relies on assumptions of geometry, etc.

Source-driven active neutron NDA methods ${ }^{34}$ employing an external neutron or gamma-ray interrogation source could be used to perform fissile material surveys and thus determine fissile content in the presence of high gamma-ray background. The technique of active neutron coincidence counting (ANCC) could be employed for the direct determination of fissile material mass. However, the applicability of a given measurement technique will depend strongly on the quantity (mass) of fissile material within the component and thus the detection limits of the technique, the presence of fertile nuclides, background $(\alpha$, n) neutrons due to the presence of light elements chlorine, fluorine, lithium, or sodium in the fuel salt, and the material composition of the component itself. Components will also need to be evaluated on a caseby-case basis to determine the neutron emission rates from spontaneous fission in isotopes such as ${ }^{244} \mathrm{Cm}$, which would be treated as background to those measurements, or as a surrogate for nuclear material, depending on concentration and chemistry.

The use of an external interrogation source could be avoided if internal neutron sources such as ${ }^{244} \mathrm{Cm}$ spontaneous fission might be used for self-interrogation of components. In that case, techniques such as Passive Neutron Albedo Reactivity (PNAR) ${ }^{35}$ or differential die-away self-interrogation (DDSI) ${ }^{36}$, which provide an indirect determination of fissile material mass via the measurement of item multiplication, could inspire new approaches to source-driven neutron interrogation.

Fissile material surveys will be performed as the components are taken outside of containment into a large transfer hatch/airlock (containment airlock system) and prior to being packaged into transfer/storage casks for dry storage or transport. Components might also be loaded into a cask while in containment due to their high radioactivity, in which case measurements of cask contents would be required.

Engineering design and interfaces will be crucial. A possible engineering solution to integrate active neutron interrogation into the containment airlock system is to create a monitoring station where the item or cask would be transferred to an NDA system for fissile content measurement prior to being transferred to the packaging system. The monitoring station would be similar to that planned for spent nuclear fuel assembly and cask monitoring at a geological repository. NDA system design should be considered during the plant design and evaluation process as part of the overall monitoring station design. It is anticipated that all sensors and electronics for the monitoring station can be external to high radiation fields. Within the family of active neutron NDA techniques, differential die-away (DDA) might also be used if there is a possibility to build a moderating assay chamber at the measurement location. The $\mathrm{DDA}^{37}$ and ${ }^{252} \mathrm{Cf}$ Shuffler ${ }^{38}$ techniques are a more direct measurement of fissile mass, as they induce fission and detect prompt and delayed neutrons, respectively.

ANCC and DDA are mature technologies. DDSI and PNAR technologies were recently developed for the assay of plutonium content in spent nuclear fuel assemblies from pressurized water reactors. However, none of these techniques have been evaluated for their applicability to MSRs, so technology development work is needed before they could be reliably deployed for this application. It is anticipated that the application of these techniques to liquid-fueled MSRs and large plant components would need the most development work since these measurement scenarios deviate to the greatest extent from traditional applications. The concept of operations for these measurements will also require consideration and development to determine how measurement results are interpreted and how they can inform nuclear material handling, processing, and storage or the potential disposition path. 


\subsubsection{Nontraditional Imaging for Standoff}

The type of applications in which imaging will be used include movement of robotic arms, movement of tools, use of tools, etc. Because of the variety of applications which would likely span from a wide-field view of an operation down to a very close zoom-in view of tightening a bolt or a screw, there will likely be opportunities for promising imaging techniques that could provide an image of appropriate resolution and survive the radiation environment. The ability to provide a useful image from a standoff distance or with a very rad-hard sensor may allow nontraditional imaging techniques to prove useful.

\subsubsection{LiDAR}

LiDAR is an acronym for light detection and ranging. ${ }^{39}$ The principle behind LiDAR is essentially the same as that for RADAR. Light pulses from a laser are transmitted, and reflections of the transmitted pulses are captured with the return time measured. Since the speed of light is known, distance from the transmitter to the reflecting object can be measured precisely. Because a laser is being used and the coherent beam direction is known, a true 3D image of surroundings can be created. This technique is widely used for large area terrain mapping, meteorological mapping, and for automotive mapping systems.

With all this capability and the potential for high-resolution mapping using a laser, LiDAR may be a valuable tool for close-in, fine work on bolt or screw removal, etc. The approach would be to locate a LiDAR system at a standoff distance, perhaps behind radiation baffles, out of the direct shine of the sources. One obvious limitation is that since this is intended to be a standoff system, shadowing of the area being imaged could occur when actuators occlude the light path. There is currently no documentation of any available system or indication that there is any ongoing development for this type of application.

\subsubsection{Ultrasonics}

Ultrasonic transmitters work on a principle roughly analogous to LiDAR, except soundwaves are used instead of laser light. When soundwaves are transmitted, the return time is measured, and the distance between the transmitter and the incident object can then be determined. One of the main issues of using ultrasound for fine imaging is the creation of a sufficiently narrow transmitted beam that would allow high resolution. Additionally, since ultrasound inherently requires the transmitter to be near the surface of the item being imaged, the transmitter/receiver cannot be at a standoff and must withstand the environment.

\subsubsection{Electronics}

Most measurements and controls for reactor maintenance require some form of electronics to provide information to the operator or commands from the operator to a piece of equipment. These electronics may or may not be colocated with the equipment, but if the measurement or control requires electronics that are exposed to radiation, they must be able to survive and function in the radiation field.

Amplifying devices are usually required for most electronics and are composed of transistors or vacuum tubes. Most of these devices are electrically three-terminal devices that allow current flowing between two of the terminals to be controlled by the voltage between the other terminal and one of the current terminals. This is typical of CMOS transistors, bipolar transistors, junction gate field-effect transistors (JFETs), vacuum tubes, etc.

Devices other than vacuum tubes rely on semiconductor properties to create a system that allows controlled current flow within the semiconductor bulk material or at some interface of the semiconductor 
with another semiconductor. Since semiconductors are usually crystal lattices, disruption of the lattice and therefore the properties of the material cause the device function to degrade. The figure below illustrates a standard CMOS process cross section. Because CMOS is complementary, it has a device that acts as a pull-down (NMOS) and one that acts as a pull up (PMOS). This allows transistors to fully implement amplifiers without necessarily using resistors as loads, and it allows relatively high-gain amplifiers to be designed and fabricated. Current flowing between the drain (D) and source (S) is controlled in both types by the gate $(\mathrm{G})$.

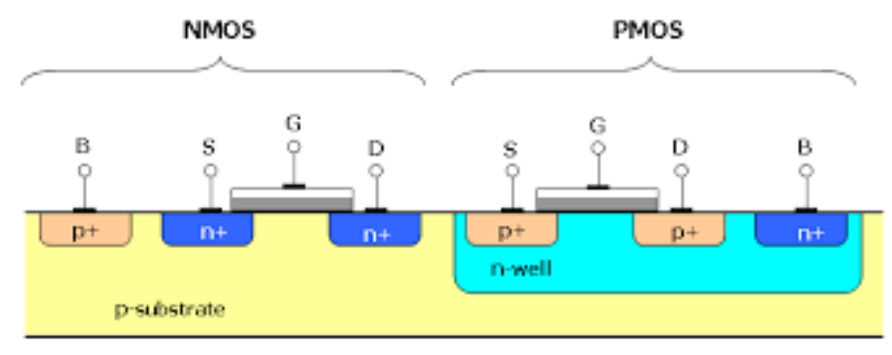

Figure 14. Standard CMOS process cross-section.

Modern standard deep-submicron processes have been shown to be somewhat radiation hard due to the thin gate oxides ${ }^{40,41}$ and the ability to further improve circuit hardness with rad-hard-by-design (RHBD) layout techniques and triple-modular-redundancy (TMR) architectural techniques. Care must still be taken in specification and design of circuits due to the change in fundamental characteristics in the bulk of the chip. With proper design, the processes can already support operation to greater than $1 \mathrm{MGy}$, but the present goal of both CERN and ITER researchers is to develop designs that can survive greater than 10 MGy.

Vacuum tubes operate differently from transistors. They generate free electrons by thermionic emission or Fowler-Nordheim emission, and they control the current flow by modulating the electric fields in the path of the current flow. The simplest vacuum tube amplifier, the triode, has been around since the early part of the $20^{\text {th }}$ century. Many refinements have been made since the early devices, but the functionality remains essentially unchanged. ${ }^{42}$

Most commercial vacuum tubes have been developed for radio or audio applications. There are a variety of different types of tubes for different functions, but most of these are no longer available since the 1970-80s. Some tubes are still being manufactured throughout the world, mainly in Russia and China, but these are primarily used for audio applications. There is an entire industry of old tube supply, and many of the obsolete devices are available in limited supply from earlier manufacture.

Recent interest in tubes has revived the idea, but on a much smaller dimensional scale. Since tubes are ballistic devices and have a mobility limited only by the electric field effect on the electrons, there is interest in using them for very high-frequency operation, hopefully into the THz region. Various geometries at the micro- and nano-scale have been tried, some with good success. Small vacuum tubes were fabricated in the 1980 s to work at high radiation doses and temperatures. ${ }^{43,44}$ These devices were tested for total dose and dose rate. TID up to $2.5 \mathrm{MGy}$ showed no observable changes, but these were admittedly not detailed operational tests. However, these data do show that extremely high TID can be obtained with these devices, but detailed operational information regarding DC characteristics has not been published. Vacuum channel transistors in which there is not an actual vacuum present are a more recent development. ${ }^{45}$ The electron path length is so small that the electrons have negligible probability of colliding with an air molecule. 
The future of reactor-hard technologies for electronics is unclear. Vacuum tubes or their descendants are an enticing technology for potential radiation hardness, but many questions are not yet answered. One of the main problems that has been overcome in silicon is the reduction in charge trapping due to thinning oxides in the scaled devices. This presents itself as reduced leakage due to smaller stray electric fields from the trapped charge. However, vacuum tubes at the size of nanometers may exhibit the same issues since they are inherently a field-effect device, but there is not sufficient data to understand the actual performance of these devices. Large tubes should be effectively immune from this effect since the glass volumes are small and far away from the metal control surfaces, thus eliminating the effects of fields generated by trapped charge.

In addition, CMOS has been successful for many reasons, but one of the most obvious is that it is complementary, which means there are both n-type and p-type devices. Either device can be used to act as a load for the other. This is the reason so much analog and digital processing has been able to be included on chips at such a relatively low power. Without the complementary load, resistors are needed as load devices, which usually results in a much higher power dissipation circuit. Tubes, however, have no such ability to be complementary. There is only an electron-emitting tube and no complementary device. This issue greatly limits the ability of vacuum tube circuits to perform extensive analog or digital functions. Even though they may be radiation hardened, there will need to be equally radiation-hard resistors to act as load devices.

\subsection{OPERATOR SUPPORT}

The availability of portable, high-resolution optics, compact high-speed data links, and fast computing resources have made the application of both VR and AR possible for remote maintenance in hot cell environments. VR provides the user with a fully electronic representation of the desired environment. AR is similar, except it does not entirely replace real surroundings. Instead, it adds contextually useful information to the input stimuli from the actual surroundings. Remote operations typically have a 10:1 effort ratio compared to locally performing activities. The chief goal of employing AR and VR technologies is to reduce the cost and time for remote O\&M tasks.

VR can be used for training or planning purposes for systems or environments that do not exist. A flight trainer can use VR to train pilots to fly aircraft prior to construction, with all the sensory input completely fabricated such as in a video game. AR, in contrast, adds extra information about real surroundings to a user interface. Examples include adding measured radiation fields to the visual representation of the work environment or compensating for visually occluded information with additional sensor or CAD information, effectively making the tooling transparent.

Remote O\&M at MSRs will apply both technologies. VR would support both training and planning by producing a digital twin - a replica of the of the containment environment's physical aspects. Digital twins could continuously update dynamic models of systems with performance data ,and depending on their simulation capabilities, they could predict remaining useful life and impending maintenance needs. The plant's remote automation system would employ the digital twin as a learning environment to repeatedly attempt virtual maintenance to develop effective procedures. Digital twin technology combined with machine learning is becoming progressively more common in industry. ${ }^{46}$ AR technology is envisioned to have a more real-time operational function in guiding ongoing maintenance activities. The containment configuration model will be continuously updated from in-containment sensors, providing plant staff detailed information on maintenance progress. Both automated systems and plant personnel will more efficiently perform their tasks with support from an AR representation of the current equipment configuration and status. 


\subsection{CYBERSECURITY AND SABOTAGE}

The issues surrounding cybersecurity and sabotage of an MSR's remote O\&M system are similar to those of other industrial process control systems. An MSR's instrumentation and control system will need to fulfill its own security and performance requirements. General cybersecurity and sabotage prevention topics, including nuclear power specific aspects, are outside the scope of this report.

The distinctive aspect of cybersecurity of an MSR's remote O\&M system is the inaccessibility of the sensors and cabling due to the high background radiation. Spoofing of sensor data is of particular concern for safeguards measurement verification. The potential to falsify safety inspection data is also of concern. If independent monitoring is to be performed, its required cabling also needs to be installed prior to plant start-up. Alternatively, regulatory information could be obtained from the plant's O\&M sensors and cabling. However, the plant systems will also contain proprietary information that the plant owners will want to control.

Once that plant has begun operation, it will not be straightforward for the full information acquisition and transmittal pathway to be independently verified, so information produced by a covertly connected plant simulation cannot be readily distinguished from actual plant data. The lack of future observability increases the importance of verifying plant configuration during construction. Several other technical measures are possible to assist in verifying the authenticity of gathered data. These measures range from incorporating seals on cameras to introducing distinctive artifacts in the field of view, as well as performing reflectometry on the cables to check whether their length or connection status has changed. Overall, the technologies for assuring the authenticity of remote O\&M system signals are mature, and the distinctive unresolved issues for MSR cybersecurity and sabotage prevention have moved past technology development and are now in the planning and execution stage. 


\section{DEVELOPMENT ISSUES}

\subsection{EVALUATION OF TECHNOLOGY GAPS}

Remote O\&M in high radiation environments has been deployed for decades, with progressively greater degrees of sophistication. Consequently, no fundamental technology gaps remain. Remote O\&M technologies continue to advance to support other high-radiation applications. The most significant issue for successfully implementing remote O\&M at MSRs is in close integration of the remote systems with design and construction planning. All systems need to be designed for installation and maintenance using remotely operated equipment. Not fully considering the capabilities and limitations of remote operations would make O\&M much more difficult. Automating maintenance activities will require substantial upfront engineering effort to develop detailed task plans.

Employing a mix of physical and virtual mock-ups for planning and training differs from the existing experience base, so it will require additional validation testing. Relying on multi-sensor data fusion to continuously update a digital twin type plant model is a state-of-the-art approach which has not previously been employed at NPPs. Shifting staff roles from performing tasks to supervising automated systems will require performance validation testing due to the implications of improper operation. Providing adequate flexibility for the plant operators using the remote O\&M system to address unanticipated challenges as they develop over the plant lifetime will be a key metric for system design. Accommodating anticipated operational occurrences and design basis events will be a basic central element of nuclear plant design. A consensus set of design basis accidents for MSRs does not yet exist, so any remote handling system will need to have flexible capabilities to allow for effective recovery from these types of events.

\subsubsection{Cameras}

There is no major technology gap for a well-designed camera system. There are several readily available CRT-based cameras that should be able to perform well, even after they have received very high doses. Additionally, there is ongoing work in CMOS camera technology that should eventually enable continued performance up to $10 \mathrm{MGy}$. Local lighting LEDs on CRT-based cameras are much less hardened, performing to only a few tens of kRad, but this can be overcome by a good system design that considers standoff workspace illumination for planned visual operations. The major market for these cameras is nuclear facilities, so the major vendors are familiar with requirements for NPPs.

\subsubsection{Cables and Interconnect}

There are no cable technology issues to be solved. Hardened flexible cables of almost any conceivable configuration can be commercially purchased, as well as nonflexible (but bendable) MI cables.

Appropriate connectors are also available. The vendors seem to be catering to nuclear facilities, as the major vendors are familiar with NPP requirements.

\subsubsection{Imaging for Standoff}

There is no indication that existing LiDAR and ultrasonic systems have been employed for the standoff imaging being considered in a radiation environment. As mentioned in the previous section describing this technology, actuators involved in the maintenance task could potentially shadow the area of interest from a laser, thus rendering the LiDAR useless. A more close-in approach would require at least part of the LiDAR system to be located closer to the area of imaging interest, which would by necessity expose it to higher levels of radiation. An approach in this case will be to locally shield the electronics in a tungsten casing while accounting for heat dissipation. Even a partially hardened system would require some 
technology development. It is not clear whether this is would be a useful investment since it has been established that optical cameras already exist that could remain for periods in the high radiation areas where maintenance would be required.

\subsubsection{Electronics}

As previously discussed, there are multiple ways for electronics to operate in high radiation environments. Custom CMOS has been shown to be a good candidate for hardened applications up to 1 GGy and beyond. The processes in which high radiation circuitry has been fabricated are available and will likely remain available for some time. Research into using the newer, small feature size processes for high-dose circuitry is ongoing since this is of paramount importance for a successful worldwide high-energy physics program. Custom circuitry would need to be designed, fabricated, and tested, which could cost a great deal of money and time. A better approach may be to adapt existing custom circuitry or commercial highrad circuitry to the requirements, which will inevitably require tradeoffs. In the big picture for a very expensive nuclear plant, a few hundred thousand dollars for a custom rad-hard chip design if needed may not amount to much overall cost and may indeed be the correct decision.

The cost effectiveness of vacuum tubes in the radiation environment is less clear. As previously discussed, small custom tubes were demonstrated to operate in a high radiation environment over three decades ago, but at this writing, there are no manufacturers, so these are not available. New technologies are being developed, but none are commercially available.

All the vacuum possibilities suffer from the fact that only small specialized systems can be made since the devices are of only a single carrier type, as previously discussed. However, there is a real possibility that for some specialized preamplifiers, interface circuits could be developed from existing vacuum tube technology. Vacuum tubes are still being made throughout the world, and circuits can be made from inexpensive, commercial devices that perform special functions such as front-end preamplifiers for fission chambers. They would need to be considered disposable and would occasionally require replacement since tubes have a limited lifetime.

\subsubsection{Aging, Replacement, and Upgrades}

An MSR NPP's lifetime is likely to exceed that of most of its SSCs. Over the course of the plant's lifetime, improved versions of components are likely to be developed. Worn out, obsolete components will need to be replaced. The technology for replacing discrete components is largely already available due to modular design. However, cabling interconnects across component boundaries and has proven to be expensive and difficult to replace in aging LWRs. Organic cable insulation can be vulnerable to fire. Cables bundled together inside of fire protective outer layers are very difficult to individually replace. Developing and demonstrating strategies and technologies to facilitate replacing both power and instrumentation cabling within containment at MSRs is recommended. Replacing large components is likely to set the size/weight requirements for the O\&M manipulators, transport casks, and the containment airlock. Maintenance/replacement task planning will need to be integrated with the component design activities. It is recommended that planning be validated by demonstrating anticipated maintenance and replacement activities at a test facility.

\subsubsection{Supply Chain}

Much of the necessary equipment for remote O\&M can be purchased commercially. In some instances, modifications to components to suit the particular needs of a facility would be anticipated. Few if any components of the O\&M system would be anticipated to be safety-related, so they would not be subject to 
an 10CFR50 Appendix B type quality assurance program. No specific remote O\&M supply chain development issues have been identified.

\subsubsection{RD\&D Implementation}

The RD\&D necessary for maturing remote O\&M at MSRs could be implemented at an industry- or government-controlled site. In the Nuclear Energy Innovation Capabilities Act of 2017, Congress directed that DOE is to maintain and develop "the facilities necessary to enable the timely research, development, demonstration, and commercial application by the civilian nuclear industry of safe and innovative reactor technology." Government-supported reactor technology RD\&D facilities are to be developed and maintained by DOE. 


\section{CONCLUSIONS AND RECOMMENDATIONS}

Highly automated remote O\&M will be vital to successful commercial deployment of MSRs. Future NPPs will not be able to afford the large amounts of labor required for O\&M in the current fleet, and even if cost were not a consideration, an MSR's containment will have much too high a radiation level for human accessibility following initial operation. Much of the technology required for remote O\&M in high radiation areas already exists, and the advance of digital technologies provides the opportunity to automate maintenance activities, shifting plant staff into an oversight role. However, integrated capability demonstration/validation and detailed planning will be required for successful implementation. Complex, highly automated maintenance in high-radiation areas has not been previously proven. Confidence in the capabilities of automated remote systems to support the diverse set of activities required over that plant's lifecycle would be substantially increased through demonstrating and validating its performance.

The conclusions reached in the historic MSR program about the need for demonstrating the reliability and remote maintainability of all of the systems and components within containment remains valid today [Spiewak 1958, reference 4]. Recently legislation (Nuclear Energy Innovation Capabilities Act of 2017) was passed emphasizing that a major purpose of the DOE's nuclear energy programs is to develop and maintain the facilities necessary to demonstrate innovative nuclear reactor technology. Consequently, it is recommended that DOE-NE establish a vendor neutral molten salt component testing and demonstration facility that incorporates remote O\&M technologies.

The Molten Salt Engineering Center (MSEC) is recommended to incorporate traditional component performance, reliability, and maintainability, as well as the continuously updated digital-twin AR elements of the O\&M system interface. An AR-plant representation would also provide for training plant staff members and the automation system to directly perform tasks and oversee automated maintenance activities. A VR plant representation would enable the machine training necessary for the plant automation system to efficiently perform O\&M tasks. It is further recommended to incorporate demonstration of technologies to efficiently recover from anticipated operational occurrences and design basis events in the MSEC capabilities. Additional modern issues such as integration of safeguards technology into plant operations should also be included in the MSEC mission. While the initial elements of the MSEC could be developed separately at multiple locations, multiple prospective MSR vendors have indicated that they intend to deploy MSRs in the United States before 2030, thus increasing the importance of an integrated demonstration of component performance, reliability, and maintainability. 


\section{REFERENCES}

1. World Nuclear News, "Advanced automation testing facility opens in Canada," http://www.worldnuclear-news.org/Articles/Advanced-automation-testing-facility-opens-in-Cana, Sep. 13, 2018, accessed Jan. 7, 2019.

2. US Atomic Energy Commission, Division of Reactor Development \& Technology, An Evaluation of the Molten Salt Breeder Reactor, WASH-1222, Sep. 1972, pp. 43-44.

3. US Atomic Energy Commission, Division of Reactor Development \& Technology, The Use of Thorium in Nuclear Power Reactors, WASH-1097, June 1969, p. 80.

4. I. Spiewak et al., "Component Development" Chapter 8 in James A. Lane, H. G. MacPherson, and Frank Maslan (editors), Fluid Fuel Reactors, Addison-Wesley for US Atomic Energy Commission, Reading MA, USA, Sep. 1958.

5. W. B. McDonald, C. K. McGlotalan, and E. Storto, Remote Maintenance Experimental Work on a Reactor System Pump, ORNL-CF-58-4-93, Oak Ridge National Laboratory, Oak Ridge, Tennessee, Apr. 23, 1958.

6. Oak Ridge National Laboratory video: Remote Maintenance of Molten Salt Reactors, https://youtu.be/uHT-w2x6dDg, Oak Ridge National Laboratory, Oak Ridge, Tennessee, accessed Jan. 7, 2019.

7. H. G. MacPherson, Molten-Salt Reactor Program Quarterly Progress Report for Periods Ending January 31 and April 30, 1960, Oak Ridge National Laboratory, Oak Ridge, Tennessee, ORNL-2973, Figures 1-1-2.

8. E. C. Hise, E. C., and R. Blumberg., "MSRE Design and Operations Report, Part X, Maintenance Equipment and Procedures," ORNL-TM-910, Oak Ridge National Laboratory, Oak Ridge, Tennessee, June 1968.

9. R. B. Briggs, Molten-Salt Reactor Program Semiannual Progress Report for Period Ending January 31, 1963, ORNL-3419, Oak Ridge National Laboratory, Oak Ridge, Tennessee, May 1963, pp. 3739.

10. R. C. Robertson, Chapter 12 "Maintenance and Repair Systems" of Conceptual Design Study of a Single-Fluid Molten-Salt Breeder Reactor, ORNL-4541, Oak Ridge National Laboratory, Oak Ridge, Tennessee, June 1971.

11. W. R. Hamel et al., "Advanced teleoperation in nuclear applications," presented at the $21^{\text {st }}$ space congress, Cocoa Beach, Florida, April 24-26, 1984.

12. ITER Organization, "ITER Remote handling," https://www.youtube.com/watch?v=Heco57jMAP0, accessed Jan. 7, 2019.

13. ITER Newsline, "European consortium to deliver 100 million euro robotic system," November 7, 2016, https://www.iter.org/newsline/-/2573, accessed Jan. 7, 2109.

14. R. Blumberg, Maintenance Development for Molten-Salt Breeder Reactors, Oak Ridge National Laboratory, Oak Ridge, Tennessee, ORNL-TM-1859, June 1967.

15. R. W. McClung, Remote Inspection of Welded Joints, ORNL-TM-3561, Oak Ridge National Laboratory, Oak Ridge, Tennessee, Oct. 1971. 
16. P. P. Holz, MSR Component Replacements Using Remote Cutting and Welding Techniques, ORNLTM-3939, Oak Ridge National Laboratory, Oak Ridge, Tennessee, Dec. 1972.

17. R. H. Guymon, MSRE Systems and Components Performance, ORNL-TM-3039, Oak Ridge National Laboratory, Oak Ridge, Tennessee, June 1973, p. 93.

18. R. W. Rosenthal, R. B. Briggs, and P. N. Haubenreich, Molten-Salt Reactor Program Semiannual Progress Report for Period Ending February 28, 1971, ORNL-4676, Oak Ridge National Laboratory, Oak Ridge, Tennessee, p. 12.

19. SECY-18-0076, Options and Recommendation for Physical Security for Advanced Reactors, ML18052B032.

20. International Atomic Energy Agency, "International Safeguards in the Design of Nuclear Reactors," IAEA, NP-T-2.9, August 2014.

21. R. C. Robertson, Conceptual Design Study of a Single-Fluid Molten-Salt Breeder Reactor, ORNL4541, Oak Ridge National Laboratory, Oak Ridge, Tennessee,.

22. I. Ribeiro et al. "The remote handling systems for ITER," Fusion Engineering and Design 86.6-8: 471-477 (2011).

23. A. Tesini, and J. Palmer. "The ITER remote maintenance system," Fusion Engineering and Design 83.79: 810-816 (2008).

24. M. J. Rennich and T. W. Burgess. "Remote handling in the Spallation Neutron Source target facility," Nuclear News 49.2: 32-36 (2006).

25. S. E. Beall, P. N. Haubenreich, R. B. Lindauer, and J. R. Tallackson, MSRE Design and Operations Report, Part V, Reactor Safety Analysis Report, ORNL-TM-732, p. 240, Oak Ridge National Laboratory, Oak Ridge, Tennessee, Aug. 11, 1964.

26. D. Collins, "Resolver vs. Encoder," https://www.motioncontroltips.com/faq-why-are-so-many-designersreplacing-resolvers-with-encoders/, Oct. 9, 2015, accessed Jan. 7, 2019.

27. W. R. Kanne, D. A. Lohmeier, K. A. Dunn, and M. H. Tosten, "Metallographic analysis of heliumembrittlement cracking of repair welds in nuclear reactor tanks," Materials Characterization 30 (1), 1993, 23-34, DOI: 10.1016/1044-5803(93)90005-G.

28. Nuclear Engineering International, "Eyes inside: radiation-tolerant CCTV," http://www.neimagazine.com/features/featureeyes-inside-radiation-tolerant-cctv/, July 12, 2013, accessed Jan. 7, 2019.

29. V. Goiffon, S. Rizzolo, Franck Corbière, Sébastien Rolando, Aziouz Chabane, et al., "Challenges in Improving the Performances ofRadiation Hard CMOS Image Sensors forGigarad (Grad) Total Ionizing Dose," 2017 International Image Sensor Workshop (IISW), May 2017, Hiroshima, Japan.

30. V. Goiffon et al., "Radiation Hardening of Digital Color CMOS Camera-on-a-Chip Building Blocks for Multi-MGy Total Ionizing Dose Environments," IEEE Transactions on Nuclear Science, Vol. 64, No. 1, Jan. 2017, pp. 45-53.

31. “Axorad Radiation Resistant Cables for Scientific \& Nuclear Applications,” http://www.axoncable.com/en/02 products/02 composite-cables/05/index.aspx, accessed Jan. 7, 2019 .

32. C. L. Hunks and D. J. Hunzmun, Radiation Effects Design Handbook, Section 3. "Electrical Insulating Materials and Capacitors,” NASA CR-1787, July 1971. 
33. L. Vermeeren and R. Van Nieuwenhove, "Theoretical study of radiation induced electromotive force effects on mineral insulated cables," Review of Scientific Instruments 74, 4667 (2003); doi: $10.1063 / 1.1622976$.

34. L. Keightley (Ed.), Good Practice Guide No. 34 Radiometric Non-Destructive Assay, Issue 2 (2012), National Physical Laboratory, United Kingdom.

35. S. J. Tobin, P. Peura, T. Honkamaa, P. Dendooven, M. Moring, and C. Bélanger-Champagne, "Passive Neutron Albedo Reactivity in the Finnish Encapsulation Context," Finnish Nuclear and Safety Authority, Helsinki, January 2018.

36. M. A. Schear, H. O. Menlove, S. J. Tobin, L. G. Evans, and S. Y. Lee, "Fissile Material Measurements Using the Differential Die-Away Self Interrogation Technique," In Proceedings of the 51st Annual Meeting of the Institute of Nuclear Materials Management, 11-15 July 2010, Baltimore, MD, USA.

37. J. Caldwell, R. D. Hastings, G. C. Herrera, W. E. Kunz, and E. R. Shunk, The Los Alamos SecondGeneration System for Passive and Active Neutron Assays of Drum-Size Containers, Los Alamos National Laboratory, LA-10774-MS, September 1986.

38. P. M. Rinard, Shuffler Instruments for the Nondestructive Assay of Fissile Materials, Los Alamos National Laboratory, LA-12105, 1991.

39. O. Cameron, “An Introduction to LIDAR: The Key Self-Driving Car Sensor," Voyage, https://news.voyage.auto/an-introduction-to-lidar-the-key-self-driving-car-sensor-a7e405590cff, May 9, 2017, accessed Jan. 7, 2019.

40. V. Goiffon et al., "Radiation Hardening of Digital Color CMOS Camera-on-a-Chip Building Blocks for Multi-MGy Total Ionizing Dose Environments," IEEE Transactions on Nuclear Science, Vol. 64, No. 1, Jan. 2017, pp. 45-53.

41. M. Menouni, M. Barbero, F. Bompard, S. Bonacini, D. Fougeron, R. Gaglione, A. Rozanov, P. Valerio and A. Wang, "1-Grad total dose evaluation of $65 \mathrm{~nm}$ CMOS technology for the HL-LHC upgrades," Published 12 May 2015 • C CERN 2015 Journal of Instrumentation, Volume 10, May 2015 Topical Workshop on Electronics for Particle Physics.

42. Journal of Vacuum Science \& Technology A: Vacuum, Surfaces, and Films 16, 1394 (1998); doi: $10.1116 / 1.581157$.

43. D. K. Lynn and J. B. McCormick, "Progress in Radiation Immune Thermionic Integrated Circuits" LA-10466-MS, Los Alamos National Laboratory, August 1985.

44. J. Byron McCormick et al., "Development of Integrated Thermionic Circuits for High-Temperature Applications" IEEE Transactions on Industrial Electronics, Vol. IE-29, No. 2, May 1982, pp. 140144.

45. S. Srisonphan, Y. S. Jung, and H. K. Kim, "Metal-oxide-semiconductor field-effect transistor with a vacuum channel, Nature Nanotechnology Vol. 7 Aug. 2012, www.nature.com/naturenanotechnology, pp. 504-508.

46. B. Marr, "What Is Digital Twin Technology - And Why Is It So Important?" https:/www.forbes.com/sites/bernardmarr/2017/03/06/what-is-digital-twin-technology-and-why-is-itso-important/ Forbes, March 6, 2017, accessed Jan. 7, 2019. 